19.310

ORNL/TM-6434

CONF-780782--3

\title{
Tokamaks Heated to High Beta
}
R. A. Dory
D. P. Berger
L. A. Charlton
J. T. Hogan
J. K. Munro

D. B. Nelson

Y-K. M. Peng

D. J. Sigmar

D. J. Strickler 


\section{DISCLAIMER}

This report was prepared as an account of work sponsored by an agency of the United States Government. Neither the United States Government nor any agency Thereof, nor any of their employees, makes any warranty, express or implied, or assumes any legal liability or responsibility for the accuracy, completeness, or usefulness of any information, apparatus, product, or process disclosed, or represents that its use would not infringe privately owned rights. Reference herein to any specific commercial product, process, or service by trade name, trademark, manufacturer, or otherwise does not necessarily constitute or imply its endorsement, recommendation, or favoring by the United States Government or any agency thereof. The views and opinions of authors expressed herein do not necessarily state or reflect those of the United States Government or any agency thereof. 


\section{DISCLAIMER}

Portions of this document may be illegible in electronic image products. Images are produced from the best available original document. 
Printed in the United States of America. Available from National Technlcal Infurmaliun Beivice

U.S. Department of Commerce

5285 Port Royal Road, Springfield, Virginia 22161

Price: Printed Copy $\$ 4.50$; Microfiche $\$ 3.00$

This report was prepared as an account of work sponsored by an agency of the United States Government. Neither the United States Government nor any agency thereof, nor any of their employees, contractors, subcontractors, or their employees, makes any warranty, express or implied, nor assumes any legal liability or responsibility for any third party's use or the results of such use of any information, apparatus, product or process disclosed in this report, nor represents that its use by such third party would not infringe privately owned rights. 


\section{MSTER}

Contract No. W-7405-eng-26

FUSION ENERGY DIVISION

TOKAMAKS HEATED TO HIGH BETA
R. A. Dory
J. K. Munro
D. P. Berger
D. B. Nelson
L. A. Charlton
$\mathrm{Y}-\mathrm{K}$. M. Peng
J. T. Hogan
D. J. Sigmar
D. J. Strickler

ORNL/TM-6434

Dist. Category UC-20 g

\footnotetext{
Date Published - July 1978

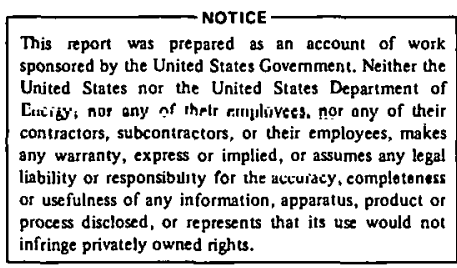

infrtinge privately owned rights.

Oeses Depariment of

Lacizy; nos any af thetr rimglivivees. nor any of their

ficter actury, comploteness

Prepared by the

OAK RIDGE NATTONAL LABORATORY

Oak Ridge, Tennessee 37830

operated by

UNION CARBIDE CORPORATION

for the

DEPARTMENT OF ENERGY 


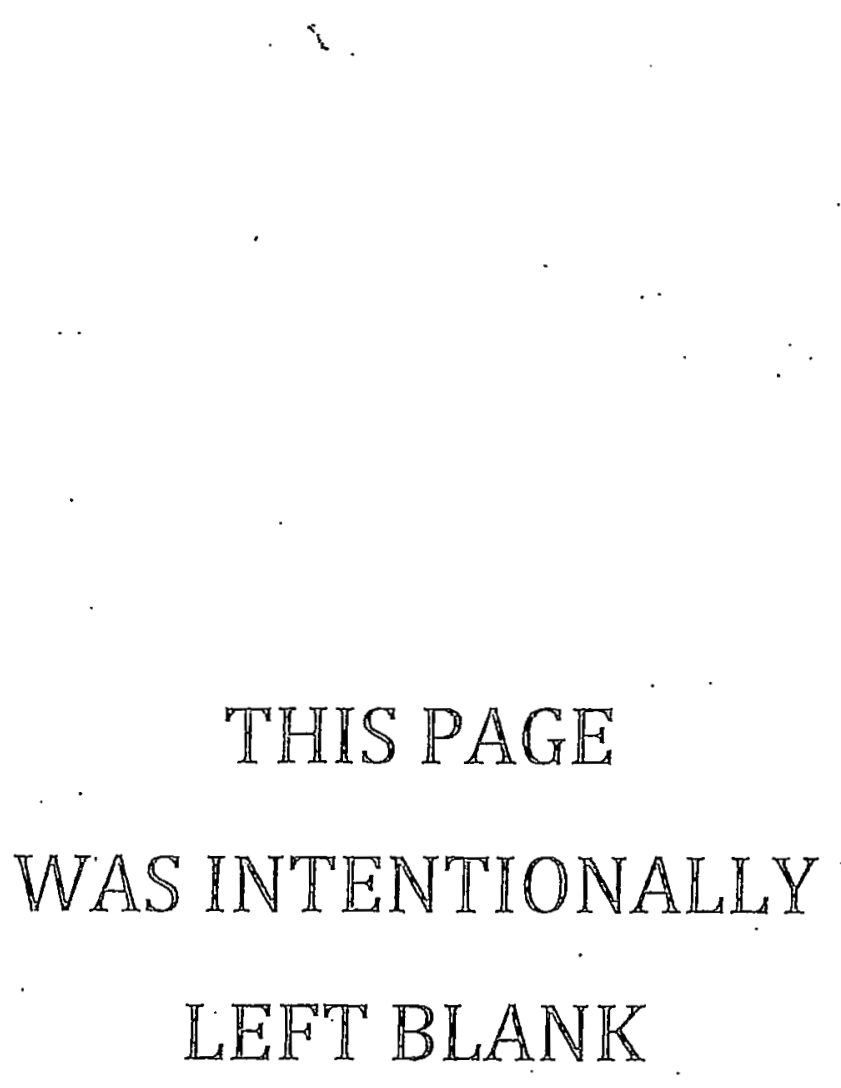




\section{CONTENTS}

ABSTRACT . . . . . . . . . . . . . . . . . . . . . 1

SUMMARY . . . . . . . . . . . . . . . . . . . . 2

INTRODUCTION . . . . . . . . . . . . . . . . . 4

1. EQUILIBRIUM STUDIES AND POLOIDAL FIELD DESIGN . . . . . . . . 6

1.1. Equilibrium studies . . . . . . . . . . . . 6

1.2. Poloidal field system design . . . . . . . . . . . 8

2. MHD STABILITY OF HIGH BETA TOKAMAK EQUILIBRIA . . . . . . . 9

2.1. Small N ideal MHD modes . . . . . . . . . . . . 9

2.2. Large $\mathrm{N}$ ideal MHD modes . . . . . . . . . . . . . . 11

3. COLLISIONAL TRANSPORT MODEL FOR FINITE BETA TOKAMAKS . . . • • 14

4. FULL SIMULATION OF TRANSPORT PROCESSES . . . . . . . . . . 16

4.1. The Oak Ridge Tokamak Transport Code . . . . . . . . 16

4.2. Test of the ORTTC model . . . . . . . . . . . . 18 ACKNOWLEDCMENTS . . . . . . . . . . . . . . . . 20

REFERENCES ........................ . . 20 


\section{ABSTRACT}

Intense plasma heating (neutral beam, wave, alpha, ...) makes high energy density tokamaks possible. This paper treats the reaction of plasma which is heated to values of beta in the range of $5-15 \%$. 
SUMMARY

Magnetohydrodynamic (MHD) equilibrium, stability, and transport calculations are used to study the stability and accessibility of tokamaks in the high energy density $(\beta=5-15 \%)$ regime [1,2] which is desirable for economical reactor operation. Results. are given from flux conserving tokamak (FCT) models $[1,2]$ where magnetic diffusion is neglected because of high plasma conductivity, classical models [3] where finite plasma conductivity and thermal transport are treated in the Pfirsch-Schliuter regime, and more complete models [4] which treat spatially resolved ( $R, Z$ ) transport, including effects from processes such as charge exchange, noucrai beam injection, and radiation.

With these studies, we have verified that there is no restriction from equ1librium considerations alone on the value of beta [5], even when attention is restricted to cases with a magnetic rotation number $q$ greater than unity at the magnetic axis and greater than 2-4 at the plasma edge. Magnetic systems have been found to shape and control the cquilibria cffectively and efficiently [6].

For these equilibria, the ideal MHD model predicts instabilities of two types if the beta exceeds critical values or if inappropriate current density profiles are used. Internal or ballooning modes which are not stabilized by nearby conducting walls appear to be controllable up to beta values of 10-15\% for sufficiently broad current (low shear) profiles $[7,8]$. External or kink modes are destabilized by broad profiles, but stability to beta values of about $8 \%$ (perhaps higher with further optimization) is possible when a conducting shell is located near the plasma, at a distance of 0.1-0.2 plasma minor radii.

After the existence of stable equilibria with rather high values of beta was demonstrated, it remained to be shown that these could be attained with reasonable experimental procedures, in the presence of plasma transport, resistivity, etc. An adiabatic plasma evolution model [3] has been used to show that FCT equilibrium sequences studied earlier [2] adequately model the dynamic development of a tokamak discharge and that FCT evolution is not sensitive (although the resulting equilibrium is) to the distribution of the injected power which carries the system from low to high beta. 
It has also been used to show that inductive skin current formation, which would otherwise occur as the plasma size and shape change under intense heating, can be avoided by programming the poloidal field coil system alone. Programming is not required for the toroidal field coils.

A more complete plasma transport model [4] has been used to verify that dissipative corrections to the simple flux conservation model do not substantially modify the sequences of plasma states during intense heating. For this purpose, the formerly one-dimensional (in plasma radius) transport model has been generalized to account for evolution of the equilibria. In order to test the codes, we have reproduced the behavior of experiments under adiabatic compression and rapid neutral beam injection heating.

With two transport models, the calculations show that the simple FCT picture presents a reasonable approximation to evolution of a tokamak discharge under intense heating on a time scale faster than the resistive skin time. The two classes are: (a) predominantly classical, such as Hazeltine-Hinton [9], Grad-Hogan [10], adiabatic heating [3], etc., and (b) nonclassical, such as the empirical [11] and anomalous (trapped particle) models [12].

An important conclusion to be drawn from the transport codes is that there is adequate control over neutral beam injection parameters to permit some modification of the current density profiles. This will allow optimization to minimize or avoid instabilities - especially if it proves possible to add a layer of low pressure current carrying plasma at the outside [13].

The pressure from the neutral beams is likely to influence overall stability, and in turn, instabilities could dominate the transport picture. Work is under way to improve the transport codes by inclusion of instability analysis modules and estimates of resulting turbulent transport, whcre available. A reliable theory is now needed for ideal and resistive modes in the presence of a resistive shell which could reduce external mode growth times to the order of the skin time for the shel]. The external form of any residual instabilities may be amenable to stabilization by feedback methods, while any internal form would be seen as enhancement to transport coefficients. 


\section{INTRODUCTION}

We define $\beta$ as $8 \pi n k\left(T_{e}+T_{i}+T_{\text {beam }}^{\text {eff }}\right) / B_{o}^{2}$ where $B_{0}$ is the vacuum toroidal field at the center $(R, Z)=\left(R_{0}, 0\right)$ of the discharge. Where a distinction is necessary, we write $\bar{B}$ for the value averaged over the plasma volume $\mathrm{V}$.

Some authors refer to a value $\beta^{*}$ which is the root-mean-square (rms) average of $\beta$. In our experience, the two values differ by a factor less than 2, and more nearly 1.2 for the broad pressure profiles which appear desirable. Use of $\bar{\beta}$ seems natural within the sphere of MHD theory, but fur reactor design it is slightiy more natural to use $\beta^{*}$ since the puwer dellvered by reactions is

$\mathrm{P} \propto \int \mathrm{n}^{2}<\sigma \mathrm{V}>\mathrm{dV} \propto \mathrm{B}_{\mathrm{O}}^{4} \int \beta^{2}<\sigma \mathrm{v}>/ \mathrm{T}^{2} \mathrm{dv} \propto\left(\beta^{*}\right)^{2}$

This equation and technological upper limits to $B_{0}$ provide the motivation for attempting to increase the usable beta values in tokamaks. It is desirable to better the values of $1-3 \%$ estimated from an early belief that beta was related to a beta poloidal by $\beta_{p}=\beta \cdot B_{o}^{2} / B_{p o l}^{2}$ (with $B_{p o l}=2 I / a$, $I=$ longitudinal current, and $a=$ discharge radius) and that $B_{p}$ was limited to $<R_{0} / a$, the toroidal aspect ratio of the plasma.

A similar rough estimate of the beta limit from hallnning modes yields $B<U / q^{2} A$ where $q$ is the safety factor for MHD modes and $U$ is of order unity. For $U$ exactly unity, this also leads to values $\beta \leqslant 3 \%$, considering engineering factors which restrict $A$ to values greater than 2.4 or so and the experience that $q \leqslant 2.5$ leads to poor confinement. Tn this paper, we present results suggesting that $U$ can be as high as perhaps 3-5, which then would permit operation in the $5-15 \%$ regime which we here refer to as "high beta."

Aside from these questions of plasma response, the technology and physics of heating processes remain as substantial areas for research and development. It is hoped that the remaining papers in this conference will lead us to effective and economical means for providing the intense heating capabilities ( $>10 \% \mathrm{~W}$ for $>10^{-1} \mathrm{sec}$ ) here assumed to be available. 
To provide some perspective for the topic of high beta tokamaks, we will mention some of the Oak Ridge work leading to the present understanding, making no effort to include contributions of others since a comprehensive review is being prepared. Salient points were:

- Callen and Dory [5] found high beta equilibria but did not have enough control of $q$ profiles to keep $q_{0}$ (value at the magnetic axis) $>1$ and $q_{s}$ (value at the plasma surface) $\geq 2.5$ as appears necessary from experiments.

- Clarke and Sigmar [1] used an expansion in $a / R_{0}$ to show that $\beta$ and $\beta_{p}$ are not inexorably tied together by a relation of the form $\beta=$ $\beta_{p} / q^{2} A^{2}$. They suggested a FCT model which allows theorists to find high beta equilibria with controlled q. This theory even suggested how plasmas might be led experimentally to such states - namely by intense heating on a time scale faster than the energy confinement time.

- Peng and Dory [2] relieved the fears of some by showing that the high beta results were not restricted to systems with small a/R and small distortion of the pressure surfaces from concentric circular toroids. They showed that there appeared to be no equilibrium restrictions on $\bar{\beta}$, even at values $\approx 50 \%$.

- Peng and Holmes [14] and Nelson and Hogan [15] provided calculations of externally heated tokamaks which showed that in progressively more realistic models, a plasma can follow FCT sequences like those exhibited by Peng and Dory.

Since 1976, the FCT process has come to be regarded as credible, although only limited direct experimental evidence is available. Because anomalous processes have occasionally been found to occur in plasmas, the possibility of direct experimental studies of FCT states in the upgraded Impurity Study Experiment (ISX-B) at Oak Ridge in the next year or two, and in the Poloidal Divertor Experiment (PDX) at Princeton when sufficient neutral beam power becomes available, appears to be an exciting opportunity to test the theory. 
Section 1 of this paper deals with equilibrium studies and poloidal field design, Sect. 2 with MHD study of high beta equilibria, Sect. 3 with classical evolution from low to high beta, and Sect. 4 with full simulation of transport processes.

\section{EQUILIBRIUM STUDIES AND POLOIDAL FIELD DESIGN}

\subsection{Equilibrium studies}

of the work discussed in this paper, this topic is the most mature and therefore is more completely avajlah]e in the literature [16], and a brief discussion of the highlights seems adequate. Early treatments of tokamak equllibrla were reviewed in Ref. 5.

The MHD equilibrium model assumes axisymmetry and the simplified equations: $\operatorname{grad} P=\bar{J} \times \bar{B} ; \operatorname{cur} 1 \bar{B}=4 \pi \bar{J}$, and div $\bar{B}=0$. Because of the assumed ax1symmetry, these may be simplified in terms of a poloidal magnetic flux function $\psi(R, Z)$ in cylindrical coordinates shown in Fig. 1 . Then $B=\hat{\phi} F(\psi) / R+\operatorname{grad} \hat{\phi} \times \operatorname{grad} \psi$, and the equilibrium equations become: $P=$ plasma pressure $=P(\psi), F=R_{\phi}=F(\psi)$ so that $P, F$, and $\psi$ are all constant on "magnetic surfaces," and

$R^{2} \operatorname{div}\left(R^{-2} \operatorname{grad} \psi\right)=-4 \pi R^{2} P^{\prime}(\psi)-F F^{\prime}(\psi)$

Equation (1) with appropriate boundary conditions determines an equilibrium, provided $P(\psi)$ and $F(\psi)$ are known from other considerations. In the present section, it suffices to choose "reasonable" profiles of $P(\psi)$, while in the transport theory sections of the paper, this is determined self-consistently from properties of the heating and transport processes.

On the other hand, the choice of $F(\psi)$ is a critical factor in obtain ing high beta equilibria. In this section, the FCT model provides the requisite (but implicit) means for finding $F$. In flux conserving dynamics, the safety factor profile $q(\psi)=F V^{\prime}<R^{-2}>/ 4 \pi^{2}$ is fixed because the magnetic fluxes move with the plasma [1]. Here, $V(\psi)$ is the volume within the magnetic surface labelled by $\psi, V^{\prime}$ may be calculated from $V^{\prime}=2 \pi \oint d l / B_{p}, B_{p}$ is the magnitude of $\overline{\mathrm{B}}_{\mathrm{p}}=\nabla \hat{\phi} \times \nabla \psi$, and $\langle\mathrm{g}\rangle=2 \pi \oint \mathrm{d} l \mathrm{~g} / \mathrm{B}_{\mathrm{p}} / \mathrm{V}^{\prime}$, where the 
integrals are taken around the surfaces $\psi(R, Z)=$ constant. Conservation of $q(\psi)$ then gives an equation of the form

$$
\left(F^{2}\right)^{\prime} g(\psi)+F^{2} h(\psi)+p^{\prime}(\psi)=0
$$

which is solved iteratively [2] in conjunction with the equilibrium equation, Eq. (1), and side conditions fixing the total magnetic fluxes in the plasma. These conditions are satisfied naturally in the later dynamic treatments, but must here be imposed separately.

It should be emphasized that the FCT assumption represents only one of many possible ways of choosing the $F(\psi)$ function, but it gives physically motivated guidance through the parameter space available for equilibrium studies. It should be stated that other means of traversing parameter space could be important because there may be some specially desirable set of parameters, for which another approach would be necessary.

To create an interesting family of FCT equilibria, a reference or initial. low beta member is chosen, for example, the case $F^{\prime}=0$ which gives $\beta_{p} \simeq 1$. Using the resulting $q(\psi)$ profile as an input to the $F$ equation (2), and raising $\beta$ by increasing $P(\psi)$ in a reasonable way, a sequence is determined as shown in Fig. 2.

Figure 2 presents the magnetic surfaces $\psi(R, Z)=$ constant, for several values of beta in a $D$-shaped geometry with toroidal aspect ratio $R_{0} / a=4$ and elongation $a_{z} / a_{R}=1.67$. The corresponding profiles of plasma pressure $P$ and toroidal current density

$\mathrm{J}_{\phi}=\mathrm{RP} P^{\prime}+\mathrm{FF} F^{\prime} / 4 \pi \mathrm{R}$

are shown in the midplane $\mathrm{Z}=0$.

The rather large deviations of the system at high beta from concentric surfaces are quite apparent and were found in all equilibria which have pressure peaked at the magnetic axis. The current density profiles in these FCT cases are exceptional in that the values at the inner side (small $R$ ) of the plasma are not reversed as is frequently true for non-FCT cases [5].

Equilibria of the type shown in Fig. 2 are ueed in the ideal MHD stahility section of this paper as inputs for the ERATO stability code. 


\subsection{Poloidal field system design}

It is shown in the stability section of this paper that the shapes of the magnetic surfaces and of the current density profiles are very important in optimizing the value of beta. Control of the latter falls into the province of injection and transport, while control of the shape is available through careful design of the external coils of the tokamak device.

Complete shape control would be possible if the plasma were surrounded by a metallic shell of sufficient conductivity and thickness. Early tukamaks had such a shell, but technological requirements make it nesessary to provide the plasma shaping fields from discrete coils located well away from the plasma. Careful choice of these currents allows adequate control of the shape, but it becomes a rather complex task to do this in a way that will accommodate the evolution of plasma from low to high beta in a single discharge.

Figure 3 shows the design carried out [16] for the ISX-B tokamak experiments at Oak Ridge. The independent control by separate programmable power supplies of the discrete conductors, which are grouped into sets, gives the desired shapes as beta varies. The coils are series/parallel connected in a way which minimizes vertical drift of the plasma and feedback circuitry is used to complete the position control. Changing the connections of the coils makes it possible to form, as well, circular and elliptical shapes and reversed D-shapes (with the corners of the $D$ at the outside) in order to test the predicted variations of stability with plasma shape.

Figure 4 shows a coil configuration which goes beyond the simple tokamak device to allow more than one discharge to be formed within a single vacuum chamber. Although many technical factors must be further analyzed and assessed, if this process could be carried out dynamically, then an alternating continuous tokamak might be possible [17] in which plasma is formed, burned, and ejected in separate parts of the chamber. In contrast to the Doublet idea, the plasmas here have opposite current direction, as would be necessary to utilize the current inducing flux changes in a repetitive fashion. 
2. MHD STABILITY OF HIGH BETA TOKAMAK EQUILIBRIA

The MHD stability properties of equilibria such as those already discussed can be described on many levels. Analysis in terms of the Mercier criterion has been given by Peng et al. [18]; this forms the most primitive filter to be applied in seeking good plasma parameters. Two further levels are discussed in detail here, while the last level, resistive MHD theory for plasmas with nonnegligible beta and toroidal curvature, is only now being pursued vigorously in the theory community.

In this section, we treat first the stability to nonlocal ideal (infinite conductivity) instabilities with long toroidal wavelength, or finite toroidal mode number $N$, where perturbations behave as $\exp (\mathrm{iN} \phi)$. Then discussion is given for short wavelength modes, including results of codes which assume very large values of $\mathrm{N}$.

\subsection{Small $\mathrm{N}$ ideal MHD modes}

Small $\mathrm{N}$ modes may be discussed in terms of two convenient simplifications: "kink modes" represent displacement of the plasma as an entity in more or less rigid form, while "ballooning modes" tend to be localized near the outer (large $R$ ) portion of the discharge. In reality, of course, there is a continuous range of modes and the properties just suggested are more representative than precise. As an operational way of distinguishing; we think of ballooning modes as those which persist even when a conducting shell is assumed to exist at the plasma edge, and kink modes as those which disappear.

The computer code ERATO [19] by R. Gruber, F. Troyon, D. Berger, and C. Bernard at the Ecole Polytechnique de Lausanne was written to study the $N=0,1,2,3, \ldots$ stability of equilibria. It performs the energy principle analysis using a finite element technique. We have applied the code to several FCT equilibrium sequences. Our study has necessarily been sketchy because the computer time required to cover a ten-dimensional parameter space is large, but we have results which suggest that stable plasma can exist to a level of $\bar{\beta} \simeq 8 \%$, corresponding to $\beta^{*}$ of $10-12 \%$.

In order to keep the study to a manageable size, we have assumed that $\mathrm{N}=0$ modes can be eliminated by clever engineering of the poloidal field 
systems, that $N=1$ modes are representative of the kink modes and that $\mathrm{N}=3$ modes represent the (finite $\mathrm{N}$ ) ballooning modes. Space and time limitations in the computers preclude higher $\mathrm{N}$ values, and the results shown later from analysis for very large $\mathrm{N}$ fall reasonably well in line with conclusions of the present study.

These conclusions are: the current density profile should be broad to minimize ballooning modes, but narrow to reduce kinks, and in the absence of other factors, the intermediate region of parameter space does not give beta values high enough to be very encouraging. However, there is another factor, which, we suggest, provides a solution: if a metallic shell is placed near the plasma (a $a_{\text {shel1 }} / a_{\text {plasma }} \sim 1.1-1.3$ ), the kink mode growth rates are reduced to the skin penetration time of the shell, which could be long enough to give effective stabilization (that is, increase of gruwth times to values large enough to be outside the scope of simple MHD theory). If the shell stabilizes or reduces the kink modes, the plasma current density profiles may then be broadened enough to raise the critical value of beta (above which occur ballooning modes) to the regimes of interest, viz. 5-10\%.

Figure 5 summarizes the situation symbolically. The ordinate $q_{s} / q_{u}$ is a measure of the breadth of the current density profile: broad profiles give low values, while peaked profiles yield large $q_{s} / q_{0}$. The three regimes separated by the solid curve are the stable region $\mathrm{S}$, the ballooning region $B$ which shows the unstable nature of peaked profiles and the kink region $\mathrm{K}$, unstable for broad profiles. With no conducting shell, the beta values in the $\mathrm{S}$ region are limited to $\sim 1 \%$ for circular plasmas; shape optimization raises this to $\sim 3 \%$ for elongated D-shaped plasmas. With a nearby conducting shell, more of the high beta region ( $\operatorname{smaller} q_{s} / q_{o}$, larger $\beta_{p}$ ) becomes accessible, as shown in the figure.

In Fig. 6 we present results for the $N=1$ and $N=3$ stab1lity of elongated $D$ equilibria of the type shown in Fig. 2. The three curves in each of the cases $N=1$ and $N=3$ provide the value of $\bar{\beta}$ above which instabilities set in. Each curve is for a fixed value of $\beta_{p}$ and on each curve the current density varies from a narrow profile at the lower right $\left(q_{s} / q_{o}=4\right)$ to a wide profile at the upper left $\left(q_{s} / q_{o}=1.5\right.$ or 2$)$. 
Because the results appear to scale as $\bar{B} \propto \mathrm{q}_{\mathrm{S}}^{-2}$, we show in Fig. 7 the value of $U \equiv \bar{B} q^{2} A$ which can be compared with the heuristic estimate of critical beta for ballooning modes $\beta_{c r i t} q_{S}^{2} A \approx 1$. As indicated in the figure, our equilibrium procedures fail to obtain results when $q_{s} / q_{o}$ is reduced too far using the q profiles chosen (see Fig. 8). A different $q$ profile would allow smaller values of $q_{s} / q_{0}$, but this would probably be at the cost of having "skinned" profiles which we have avoided as being likely to be more unstable.

\subsection{Large $N$ ideal MHD modes}

Codes of the ERATO type are restricted to studies of small values of the toroidal mode number $\mathrm{N}$ because of limited resolution. To go beyond values $N=1,2,3,4$, and perhaps 5 , it has been necessary to seek another approach. An appropriate complementary analysis has been carried out by Nelson and colleagues [8] who have provided a code called BALOON based on asymptotic analysis - an expansion in $1 / \mathrm{N}$.

To the lowest significant order in this parameter, an ordinary differential equation gives the $\psi$ component $\mathrm{X}$ of the perturbation in the form

$B_{p} \partial / \partial \ell\left(B_{p} P \partial X / \partial \ell\right)-(Q-\lambda) X=0$

with $X \rightarrow 0$ as $|\ell| \rightarrow \infty$, where $\ell$ is arc length in the poloidal direction. Here $\mathrm{P} \equiv|\nabla \psi|^{-2}+s|\nabla \psi|^{2} / \mathrm{B}^{2}$, and $\mathrm{Q}=-2 \mathrm{p}^{\prime} \mathrm{B}^{-2} \partial / \partial \psi\left(\mathrm{p}+\mathrm{B}^{2} / 2\right)-s F \mathrm{p}^{\prime} \mathrm{B} \partial / \partial \ell$ $\left(B^{-2}\right)$, while $s=(\partial / \partial \psi) \int_{0}^{l} d l B_{p}^{-1} F^{-2}$ is a measure of the shear. If this equation has no negative eigenvalues $\lambda$ when solved on each magnetic surface within the plasma, then the equilibrium is stable to ballooning modes at very large $N$. The next orders in $1 / \mathrm{N}$ give corrections to $\lambda(\psi)$ based on the radial extension of the mode. These corrections are stabilizing and proportional to $1 / \mathrm{N}$; thus this analysis shows that high $\mathrm{N}$ modes become monotonically more unstable as $N$ increases to infinity. Within the framework of asymptotic theory, a plasma thus stable to $\mathrm{N}=\infty$ should be stable also toward lower $N$ "internal" modes for which the perturbations fall to zero at the plasma edge. This analysis has so far not treated cases with a finite vacuum region surrounding the plasma and we must suppose provisionally that the low $N$ treatment discussed earlier is adequate to complete the study of ideal MHD instabilities. 
Computation of Eq. (4) has been carried out for several types of equilibria and comparisons made with the results of ERATO and PEST for low $N$ modes. In every case tested, modes with $N \rightarrow \infty$ have a lower $\beta_{\text {crit }}$ (marginally stable $\bar{B}$ ) than do $N=3$ internal modes. Since the difference in $\beta_{\text {crit }}$ is usually less than $25 \%$ for the two kinds of modes, the high $N$ analysis and the BALOON code provide an excellent sieve for studying internal mode stability, even if ideal MHD theory is not considered physically credible for studying very short wavelengths. The computer time for BALOON is at least an order of magnitude less than that required for the finite element codes.

Simple dimensional analysis of Eq. (4), ignoring shear, leads to the estimate $B_{\text {crit }} \sim 1 / \mathrm{Aq}^{2}$, where $A$ is aspect ratio and $q$ the safety factor at Lhe flux surface where the mode concentrates. Onc of our aims has been lu investigate the accuracy of this estimate when $A, q$, shape, and profiles are varied. Another aim has been to determine the role of shear, which appears as $s$ in Eq. (4) in both stabilizing and destabilizing roles.

As to the first aim, the simple formula is quite accurate for predicting variation of $\beta_{\text {crit }}$ with $A$ and $q$ when other equilibrium parameters (surface shape, profile width) are held as constant as possible. Thus one expects the highest $\beta_{\text {crit }}$ to be achieved by low aspect ratio (tight torus) and the lowest $q$ consistent with Mercier stability, which is in fact necessary for stability $(\lambda \geqslant 0)$ according to Eq. (4). Inw, almost constant $q$ requires broad current profiles and low $\beta_{\text {pol }}$; however, the shape of the flux surfaces can cause an order of magnitude change in $\beta_{\text {crit }}$. This is illustrated by Fig. 9 which plots the quantity $\beta_{\text {crit }} A^{2}$ vs fiux surface triangularity for two different classes of equilibria: the analytic Solov'ev equilibria, and sequences of FCT equilibria in which the $p$ and $q$ profiles are prescribed. In both types $p(\psi)$ is chosen to be a linear funclion. It can be seen from the figure that for $D$-shaped equilibria the $\beta_{\text {crit }}$ can be three times greater than that given by the formula. (This value is attained with an elongation of about 1.6. With less elontion the $\beta_{\text {crit }}$ is reduced.) On the other hand, for reversed D-shaped equ1libria $\beta_{\text {crit }}$ is only one-third of that predicted by the formula. (This is achieved without elongation. With elongation of the reversed $D$, $\beta_{\text {crit }}$ drops.) 
As to the second aim, so far we have found shear to be virtually irrelevant to stability of high ballooning modes. This can already be seen in the analysis leading to Eq. (3), which shows that the mode conforms to the local field line pitch and is not localized by shear. The calculations confirm this. We have studied equilibria with prescribed $p$ and $q$ profiles, keeping $q_{s} / q_{o}$ fixed but varying the shear $d q / d \psi$ where the mode concentrates, by changing the function $q(\psi)$.

The results of two such calculations are shown in Fig. 10, the first with circular cross section and the second with a D-shaped cross section. For both the calculations $\mathrm{p}(\psi)$ is linear; $\mathrm{q}(\psi)$ has the form $\mathrm{q}(\psi)=\mathrm{q}_{0}+$ $\mathrm{q}_{1} \psi+\mathrm{q}_{2} \psi^{2}$; and both $\psi_{\text {axis }}$ and $\psi_{\text {edge }}$ are the same for all equilibria. Thus $q_{a x i s}$ and $q_{e d g e}$ can be fixed, but the local shear $q^{\prime}(\psi)$ is varied by picking $\mathrm{q}_{0}, \mathrm{q}_{1}$, and $\mathrm{q}_{2}$ appropriately. For all these equilibria the instability concentrated near the outside edge of the plasma. As shown in Fig. 10, the shear there was varied by a factor of two, but the $\beta_{\text {crit }}$ varied only about $10 \%$ in the circular equilibria, increasing slightly with shear, and $15 \%$ in the D-shaped ones, decreasing with shear. We conclude from such calculations that shear is unimportant for stabilizing ballooning modes.

Although without recourse to computation we cannot yet predict accurately what the $\beta_{\text {crit }}$ for stability to internal modes will be for a given family of equilibria, favorable properties have been discovered. These include small aspect ratio A (tight torus), $q_{\text {axis }}$ large enough to satisfy the Mercier criterion ( $q_{\text {axis }} \gtrsim 1$ ), $q_{\text {edge }}$ as small as possible (for example, a stable circular cross section equilibrium with $\mathrm{q}_{\text {edge }}=$ $1.01, A=4$, and $\beta=10 \%$ has been computed), and $D$-shaped cross section with elongation between $1.5: 1$ and $2: 1$. For such equilibria $\beta_{\text {crit }}$ exceeding $15 \%$ is possible. Of course, as stated in sect. 2.1, some of these requirements are in conflict with those needed for stability to external kink modes. Practical attainment of finite beta stable tokamaks will require compromise and careful adjustment of the equilibrium parameters. 


\section{COLLISIONAL TRANSPORT MODEL FOR FINITE BETA TOKAMAKS}

A detailed exposition of this work is in preparation [20]; within the present paper the approach is indicated schematically and results of some first studies are discussed.

This work applies a single fluid resistive MHD model, including heat flow and magnetic evolution, to a finite beta tokamak device. Analysis is therefore restricted to the collisional (Pfirsch-Schlüter) regime. The insight realized from this simple model has already begun to affect the more realistic (and complex) work discussed in Sect. 4 of this paper. The basic equations are

$$
\begin{aligned}
& \frac{d \rho}{d t}+\rho \nabla \cdot \bar{u}=Q \\
& \rho \frac{d u}{d t}+\nabla p=\bar{J} \times \bar{B} \\
& \frac{d P}{d t}+\gamma P \nabla \cdot \bar{u}=(\gamma-1)[\bar{J} \cdot \eta \cdot \bar{J}+Q-\nabla \cdot \bar{q}] \\
& \frac{\partial \bar{B}}{\partial t}+\operatorname{curl} \bar{E}=0, \bar{J}=\operatorname{curl} \bar{B}, \nabla \cdot \bar{B}=0 \\
& \bar{E}+\bar{u} \times B=n \cdot \bar{J} . \\
& q=-x_{\perp} \nabla_{\perp} T+x_{n} \hat{b} \times \nabla T-x_{\|} \nabla_{\|} T
\end{aligned}
$$

in standard notation. On the time scales of interest for transport processes, the $\rho d u / d t$ term is much smaller than $\nabla P$ and $J \times B$ eo that the evolution of the system is essentially determined by continunus applicition of the force balance equation $\nabla \mathrm{P}=\mathrm{J} \times \mathrm{B}$ [10]. This fart, taken with the ordering of the transport coefficients for the three orthogonal directions $x_{\|} \gg x_{m} \gg x_{1}$, lcads to a closed set of flux-surface-averaged equatious which determine the system evolution.

The flux-surface-averaged equations are applied to solve for convenient state variable combinations $\rho V^{\prime}, P\left(V^{\prime}\right)^{\gamma}$, and $q$ as functions of independent variables $t$ and $\psi_{t}$, the toroldal flux variable. The resulting set of equations consists of three coupled explicitly parabolic ( $t$ and $\psi_{t}$ ) equations for the state variables and the surface average of the 
equilibrium equation, Eq. (1). A time splitting procedure is used to advance these on their natural time scale (diffusion time), while the only two-dimensional equation, Eq. (1), is solved only as required to keep up with changes in the equilibrium geometry. The flow velocity and full transport coefficients may be obtained as data useful in interpreting the results of advancement of the state variables.

We describe briefly two applications of the theory just discussed: first, an adiabatic or flux conserving problem and then a related example where thermal transport is also included. In both cases we demonstrate FCT or FCT-like heating of a plasma initially at low beta, as intense external heating is applied.

Figure 11 shows two adiabatic sequences which differ only in the profile assumed for the externally applied energy source, $Q(\psi)$. In the first time series, with $Q(\psi)$ peaked at the magnetic axis, a "normal" FCT sequence results, with a pressure peaked at the axis as shown earlier and current density profile distorted because of the high beta value, but otherwise as usual. In the second series, however, which might correspond to neutral beam injection with too low a beam energy or too high a plasma density, the $Q(\psi)$ is peaked well away from the axis. As the beta rises, the pressure profile becomes hollow and the toroidal current density quite pathological, having a form that is very likely to lead to instabilities. An interesting feature of the flux surfaces in this case is that those in the high plasma pressure region are shifted outward as usual while those at the cold center are not.

Figure 12 presents results of a similar intense heating case which achieves $\beta \sim 15 \%$ even in the presence of classical thermal transport. In order to display the capabilities of the code, an attempt is made to sustain the high beta, after the beam is turned off at $\mathrm{T}=0.3$ scaled units, by applying major radius compression. The history of the stored energy in the plasma in Fig. 12(b) shows that the pressure did hold up longer with compression, but with the parameters used here, the discharge is only extended by about $20 \%$ of an energy confinement time. 


\section{FULL SIMULATION OF TRANSPORT PROCESSES}

\subsection{The Oak Ridge Tokamak Transport Code}

The Oak Ridge Tokamak Transport Code (ORTTC) has been used to study how well the processes in a real tokamak with nonzero resistivity, particle and energy transport, impurities, etc., compare with the idealized FCT processes. In brief, the conclusions are that achieving high beta is possible, but that this depends critically on control of impurities. A detailed discussion of the code and the pertinent results has been given in a very recent report by J. T. Hogan [4] in which numerous relevant references are to be found. 'lhis section gives a brief review of that work.

The ORTTC includes the best available and practical representation of the physical processes known or suspected to be important in present and near-term future tokamak experiments. These processes are:

- neoclassical, empirical, and selected anomalous transport models;

- dynamics of magnetic surfaces in $(R, Z)$, adiabatic compression;

- neutral particle transport;

- neutral beam injection processes;

- impurity diffusion and atomic level dynamics;

- radiative processes;

- plasma-wall interaction, sputtering, desorption, reflection, recyciling, etc.;

- resistive MHD instability modes, sawtooth, nonlinearly saturated $\mathrm{m}=2, \mathrm{n}=1$.

The corresponding theories and modules are based on the work of many contributors who are acknowledged in the report.

'l'hese factors are integrated by means of a so-called $1 \frac{1}{2}$-dimensional transport calculation where magnetic surfaces are determined by appeal to the equilibrium equation, while the transport processes are treated as a one-dimensional problem in the magnetic flux coordinate. Transport in a magnetic surface (along the field lines) is assumed to be instantaneous because of the much larger coefficients which apply, so that the surfaces are taken to be isothermal and isobaric $[T=T(\psi)$, and $P=P(\psi)]$. The 
equilibrium problem and the transport problem are solved alternately and repetitively in what is effectively a time-splitting method.

In a little more detail, the procedure is:

1. solve the equilibrium equation, given $P(\psi)$ and $q(\psi)$;

2. determine the required surface-averaged quantities;

3. perform a diffusion time step;

4. solve the equilibrium equation with new inputs;

5. rearrange the state variables on new flux surfaces (adiabatically);

6. repeat from step 2 above.

The state variables which are advanced in the diffusion step are $\mathrm{n}_{e}$, $n_{z}$ (the density of all excitation states of some one representalive impurity atom), $\mathrm{T}_{e}, \mathrm{~T}_{i}$, and an average or effective poloidal field variable $\mathrm{B}_{\mathrm{p}}^{(\mathrm{eff})}$. The hydrogen ion density is determined from a neutrality condition, cold hydrogen atomic density $n_{0}$ from a kinetic slab model, the excitation levels of the impurity species from a coronal equilibrium model, and the injected high energy neutral population from a Monte Carlo deposition model with a Fokker-Planck calculation for the distribution. .

The equations for the equilibrium step have been given in Sect. 1; however, a modification is made to the inputs since the adiabatic step leading from one equilibrium to the next provides $q(\psi)$, rather than $F(\psi)$, where the safety factor profile $q(\psi)$ is found from Maxwell's equations for the effective poloidal field variable $B_{p}^{(e f f)} \equiv q(\psi) / 16 \pi^{4}<R^{-2}>F \rho$, where the average radius $\rho$ of a given magnetic surface is defined in terms of its volume by $\rho \equiv\left[V(\psi) / 2 \pi^{2} K_{0}\right]^{1 / 2}$. A procedure develuped by Grad, Hu, and Stevens [21] is then used to obtain the magnetic surfaces with given boundary values of $\psi$, or external plasma shaping conductors.

The actual equations solved by ORTTC have the form:

$\partial n_{e} / \partial t+\rho^{-1} \partial / \partial \rho\left(\rho<\Gamma e^{>}\right)=\left\langle\Sigma e^{>}\right.$(electron density) 
$3 / 2 \mathrm{H}^{-1} \partial / \partial t\left[\mathrm{HP}_{i, e}\right]+\left(1 / \mathrm{V}^{\prime}\right) \partial / \partial \psi\left[\mathrm{V}^{\prime}\left(\mathrm{q}_{i, e}+5 / 2 \Gamma_{i, e^{\mathrm{T}}} \mathrm{i,e}\right)\right]$

$$
\begin{aligned}
& =\left\langle Q_{i, e}^{\mathrm{INJ}, \propto}\right\rangle-\left\langle Q^{\mathrm{RAD}}\right\rangle_{e}+\left\langle Q^{\mathrm{OH}}\right\rangle_{e} \pm\left\langle Q^{\mathrm{COUL}}\right\rangle \\
& \pm\left(\Gamma_{e} / \mathrm{n}_{e}\right) \partial \mathrm{P}_{i} / \partial \psi \pm \mu_{i} \mathrm{~T}_{i} \mathrm{~A}_{1 i}
\end{aligned}
$$

(electron, hydrogen, ion pressures)

$\partial / \partial t B_{p}^{e f f}=\partial / \partial \rho\left[\left(n / \rho G \mu_{0}\right) \partial / \partial \rho\left(G^{\prime} \rho B_{p}^{e f f}\right)\right]$ (field)

where $H=\left(V^{\prime}\right)^{5 / 3}, V^{\prime}=d V / d \psi, G$ and $G^{\prime}$ are scale factors, $\Gamma_{i, e}$ are the transport coefficients, the $\mu_{i}$ and $A_{1 i}$ represent off-diagonal terms in the full transport equations [22] and the Q's represent terms for power lost or gained through injection, alpha particles, radiation, ohmic heáting, and Coulomb collisions.

\subsection{Test of the ORTTC Model}

Results of this model, mutatis mutandis, have been compared with experimental data from the Oak Ridge Tokamak (ORMAK) experiment at Oak Ridge and the Adiabatic Toroidal Compressor (ATC) experiment at Princetnn. These comparisons give a level of confidence in the procedure used to treat the neutral injection processes and the spatially corrected transport. Both of these are highly Important for reliability of the extrapolation to high beta because the heating process is necessary for attaining this regime, and the known magnetic surface distortions at high beta have the potential of strongly affecting the transport.

For the ORMAK experiment, comparison with ORTTC suggests a reason for the rather puzzling result that the neutral injection process heated the ions very effectively, while the observed electron temperatures frequently fell well below the predictions of simple injection theory [23].

In Fig. 13 are presented results from two ORTTC runs with parameters chosen to represent a series of ORMAK shots at low current and therefore low ohmic heating power. In Fig. 1.3(a), the impurity species is a low $\mathrm{Z}$ (oxygen) population of density $7 \times 10^{12} \mathrm{~cm}^{-3}$, which leads to a rather high electron temperature because the impurity is essentially fully stripped 
throughout much of the discharge: On the other hand, in Fig. 13(b) are shown the corresponding data for a run in which the impurity is tungsten at a density of $10^{10} \mathrm{~cm}^{-3}$ representative of spectroscopic estimates [24]. In this case, the impurity is not fully stripped, the resulting line radiation holds the electron temperature down to values as observed, and the decay times after turnoff of the beam are about as observed. Clearly the high $Z$ impurities can dominate discharges even when their relative concentration is as small as $5 \times 10^{-4}$.

In these calculations, the ion thermal diffusion coefficient and plasma resistivity are assumed to be neoclassical, while the electron thermal coefficient and the density diffusion coefficients have Artsimovich's pseudoclassical folm.

For the ATC experiment, comparison with ORTTC suggests a reason for the observed deviation [25] of the experimental results from simple adiabatic compression arguments. As in the ORMAK case, impurities in the discharge provide a credible explanation, even at a relative concentration as small as $5 \times 10^{-4}$.

Figure 14 presents results of simulation runs of ATC compression experiments. In Fig. 14 (a) it is shown that with no impurity population, a substantial pressure increase is realized when a 2:1 compression is applied. On the other hand, with a density of $10^{10} \mathrm{~cm}^{-3}$ of molybdenum, it is found that compression heating as modelled here is unable to cope with the line radiation and a net reduction of the plasma pressure results. The simulation results are believed to be consistent with the data available for this mode of nperation, the details of which are given in Ref. 4. The transport coefficients used were neo- and pseudoclassical as before. As an example of the response of a tokamak to massive neutral beam injection, a study has been carried out of the response of the PDX tokamak experiment to a hypothetical heating rate of $12 \mathrm{MW}$ applied to an initial state having central temperatures and densities of $1 \mathrm{keV}$ and $2 \times 10^{14} \mathrm{~cm}^{-3}$. In Fig. 15 are presented the pressure as function of major radius and time and the evolution of the safety factor profile as function of beta, which is remarkably well preserved in this nonideal case. of course, q does vary near the plasma edge where the temperature is low and flux is not well 
conserved. As in other examples, inclusion of high $Z$ impurities could make the approach to high beta less effective than that shown.' Provided the PDX poloidal divertor system works well, the present assumption of negligible impurities and neo/pseudoclassical transport could prove to be well founded.

\section{ACKNOWLEDGMENTS}

We would like to acknowledge useful discussions with J. F. Clarke, L. A. Berry, J. D. Callen, D. Dobrott, and H. Grad.

The ERATO ideal MHD instability code was used for many of the results discussed, and we thank F. 'Trnynn; R. Gruber, and the Centre de Reclierche en Physiques des Plasmas, Ecole Polyterhnique de Lausanne, Switzerland for making it available and teaching us its use.

\section{REFERENCES}

[1] ClARKE, J. F., SIGMAR, D. J., Phys. Rev. Lett. 38 (1977) 70.

[2] DORY, R. A., PENG, Y-K. M., Nucl. Fusion 17 (1977) 21.

[3] NELSON, D. B., SIGMAR, D. J., BATEMAN, R. G., UCKAN, N. A, , paper presented at the Workshop on Finite $B$ Tokamaks, International School of Plasma Physics, Varenna, Italy, September 1-10, 1977; Oak Ridge National Laboratory Rep. ORNL/TM-6273 (1978); SIGMAR, D. J., VAHALA, G. V., Oak Ridge Nationa1 Laboratory Rep. ORNL/TM-6040 (1978).

[4] HOGAN, J. T., Oak Ridge National Laboratory Rep. ORNL/TM-6049 (1.978); MUNRO, J., et al., Oak Ridge National Laboratory Rep. ORNL/TM-5262 (1977).

[5] CALlen, J. D., DORY, R. A., Phys. Fluids 15 (1972) 1523.

[6] PENG, Y-K. M., DORY, R. A., STRICKLER, D. J., Oak Ridge National Labulalury Rep. URNL/'L'M-5648 (1977).

[7] BATEMAN, R. G., PENG, Y-K. M., Phys. Rev. Lett. 38 (1977) 827.

[8] DobrotT, D., et al., Phys. Rev. Lett. 38 (1977) 829.

[9] hazeltine, R., hinton, F., Rev. Mod. Phys. 48 (1976) 239.

[10] GRAD, H., HOGAN, J. T., Phys. Rev. Lett. 24 (1970) 1337. 
[11] APGAR, E. A., et a1., Plasma Physics and Controlled Nuclear Fusion Research (Proc. 6th Int. Conf. Berchtesgaden, 1976) I, IAEA, Vienna, 247; GORBUNOV, E., MIRNOV, S. V., STRELKOV, S., Nucl. Fusion 10 (1970) 43.

[12] KADOMTSEV, B. B., POGUTSE, O. P., Nucl. Fusion 11 (1971) 67.

[13] D'IPPOLITO, D. A., et al., FOM-Instituut voor Plasmafysik Rep. I. R. 77/036 (1977).

[14] HOLMES, J., PENG, Y-K. M., DORY, R. A., paper presented at the Plasma Simulation Conference, Monterey, California, June 1978.

[15] HOGAN, J. T., NELSON, D. B., paper presented at the Controlled Fusion Theory Meeting, Gatlinburg, Tennessee, April 1978.

[16] PENG, Y-K. M., et al., Oak Ridge National Laboratory Rep. ORNL/TM- (in preparation); Plasma Physics and Controlled Nuclear Fusion Research (Proc. 6th Int. Conf. Berchtesgaden, 1976) II, IAEA, Vienna (1977), 369.

[17] PENG, Y-K. M., Oak Ridge National Laboratory Rep. ORNL/TM-6319 (1978).

[18] PENG, Y-K. M., DORY, R. A., NELSON, D. B., SAYER, R. 0., Phys: Fluids 21 (1978) 467.

[19] BERGER, D., GRUBER, R., TROYON, F., paper presented at the Second European Conference on Computational Physics, Garching, Federal Republic of Germany, April 27-30, 1976.

[20] NELSON, D. B., GRAD, H., Oak Ridge National Laboratory Rep. ORNL/TM-6094 (1978); GRAD, H., HU, P. N., paper presented at the Workshop on Finite $\beta$ Tokamaks, International School of Plasma Physics, Varenna, Italy, September 1-10, 1977.

[21] GRAD, H., HU, P. N., STEVENS, D. C., Proc. Nat. Acad. Sci. USA $\underline{72}$ (1975) 3789.

[22] Hinton, F. L., HAZEltine, R. D., Rev. Mod. Phys. 48 (1976) 239.

[23] MURAKAMT, M., et a1., Phys. Rev. Lett. 39 (1977) 615.

[24] ISLER, R., et a1., Phys. Lett. 63A (1977) 295.

[25] BOL, K., et al., Phys. Rev. Lett. 29 (1972) 1495. 


\section{FIGURE CAPTIONS}

Fig. 1. Coordinate system used in this paper.

Fig. 2. Sample FCT sequence. In the R-Z plane, flux contours are shown for (a) $\beta=1.2 \%$, (b) $\beta=10.7 \%$, (c) $\beta=18.8 \%$. Also shown are the pressure and current density profiles as functions of $R$ at $\mathrm{Z}=0$ for these cases.

Fig. 3. Poloidal field system for ISX-B. Dashed lines indicate coil groupings to create circular, elliptical, D-shaped, and reverser v-chapcd cquilibria. Heavy lines indicate plasma surface.

Fig. 4. Continuous tokamak equilibrium. Upper plasma: low beta (creation stagc). Lower plasma: high beta (burn stage). 'he current directions in the two cases are opposite.

Fig. 5. Schematic stability diagram. Solid line: infinite vacuum region. Dotted line: wall near plasma.

Fig. 6. Beta limits for $N=1$ and 3 , as a function of $q_{s}$, safety factor at the plasma surface. The narrow (hi.gh $q_{s} / q_{\Omega}$ ) current density profiles are Indlcaced by $n$, wide by $w$.

Fig. 7. Beta limits of Fig. 6, shown in terms of $U \equiv B q_{S}^{2} A$, as a function of (a) $q_{g} / q_{o}$ and (b) $q_{s}$. Also shown is (c) $B_{p}$ vs $q_{0}$; the rurves are essentially independent of $q_{s} / q_{0}$.

Fig. 8. Safety factor profiles used. The square points represent a "narrow" profile, cirr.les "medium," and triangles "wide".

Fig. 9. Effect of triangularity on beta limits for $N=\infty$. Circled points are for the Solov'ev equilibrium, $x$ points for FCT equilibria. 
Fig. 10. Effect of shear on beta limits for $N=\infty$. The shear parameter used is ( $\left.\psi_{\text {edge }}-\psi_{\text {axis }}\right) \mathrm{q}\left(\psi_{*}\right) \mathrm{dq} /\left.\mathrm{d} \psi\right|_{\psi_{*}}$, where $\psi_{*}$ is the most unstable flux surface (peak of the mode).

Fig. 11. Adiabatic evolution to high beta with heating profile peaked (a) on the magnetic axis and (b) off-axis.

Fig. 12. Intense heating with classical transport. (a) Magnetic surfaces as function of time or beta. The top two plots show the intense heating phase; the bottom two show the compression phase after external heating is turned off at $\mathrm{T}=0.28$ arbitrary time units. (b) Corresponding time history of pressure for cases with and without compression.

Fig. 13. Test of ORTTC for intense neutral beam heating. (a) Electron heating in the ORMAK neutral beam experiments. It is assumed that there are no heavy metal impurities present; the resulting temperature rise exceeds the experimental values. Injection is assumed to begin at $20 \mathrm{msec}$, and the injection current is cut off at $100 \mathrm{msec}$. (b) ORMAK heating experiments as in (a), except the tungsten line radiation loss is included. The $\mathrm{T}_{e}$ rise saturates quickly and holds down the $\mathrm{T}_{i}$ heating as well.

Fig. 14. Test of ORTTC: compression and transport in ATC with (a) no impurity and (b) molybdenum at $10^{10} \mathrm{~cm}^{3}$.

Fig. 15. ORTTC results for intense neutral beam heating in a device with PDX parameters and 12-MW beam power. (a) Pressure vs major radius for $t=0$ to $150 \mathrm{msec}$ and $q$ as function of $\left(V / 2 \pi^{2} R_{0}\right)^{1 / 2}$ for the same times (notice approximate flux conservation). (b) $\bar{\beta}$ vs time for three transport models; classical (top), empirical (middle), collisionless instability (bottom). The oscillations in the latter two occur because $t_{p} \propto n_{e}$ in those cases. 


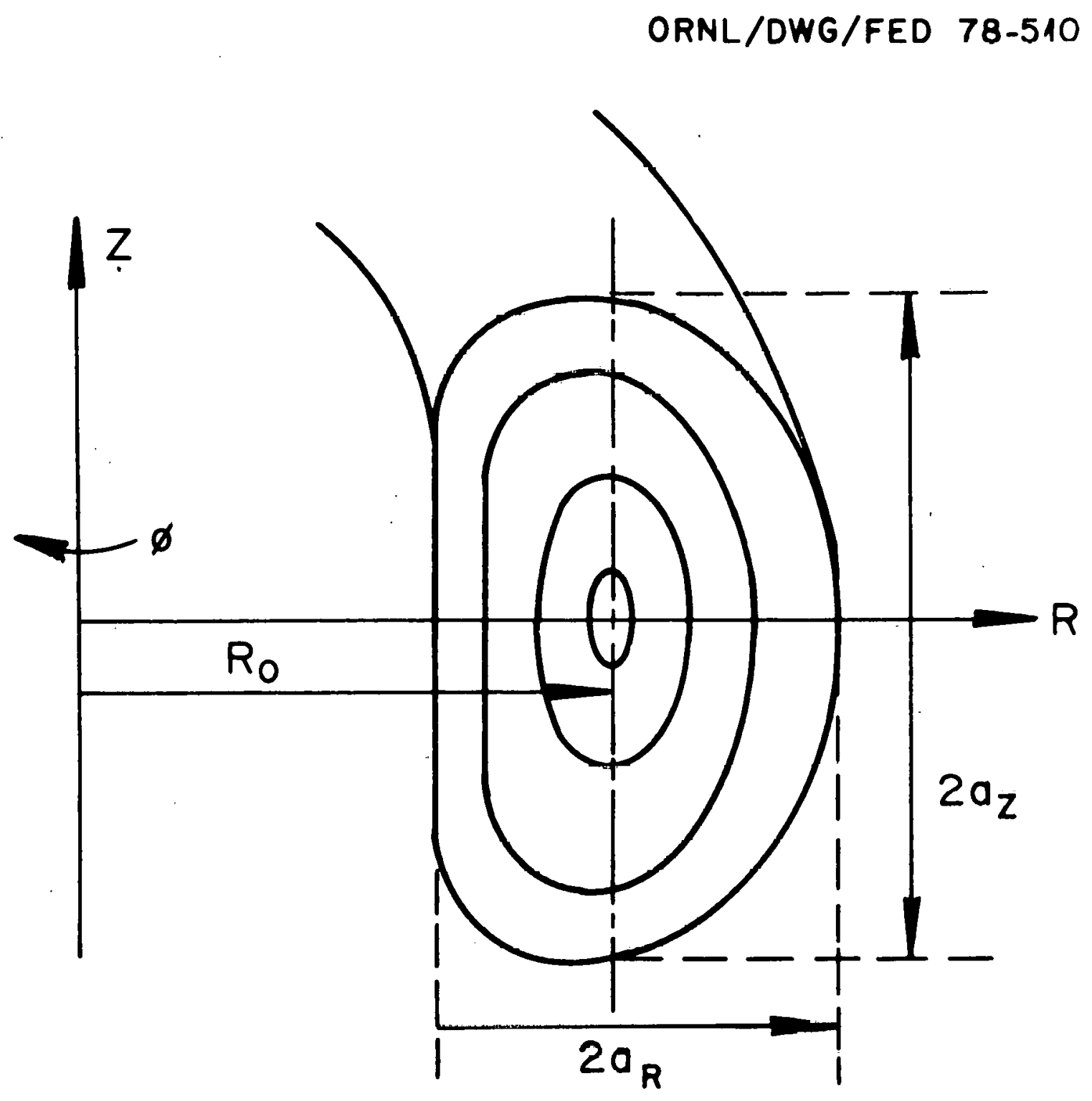

Fig. 1. 

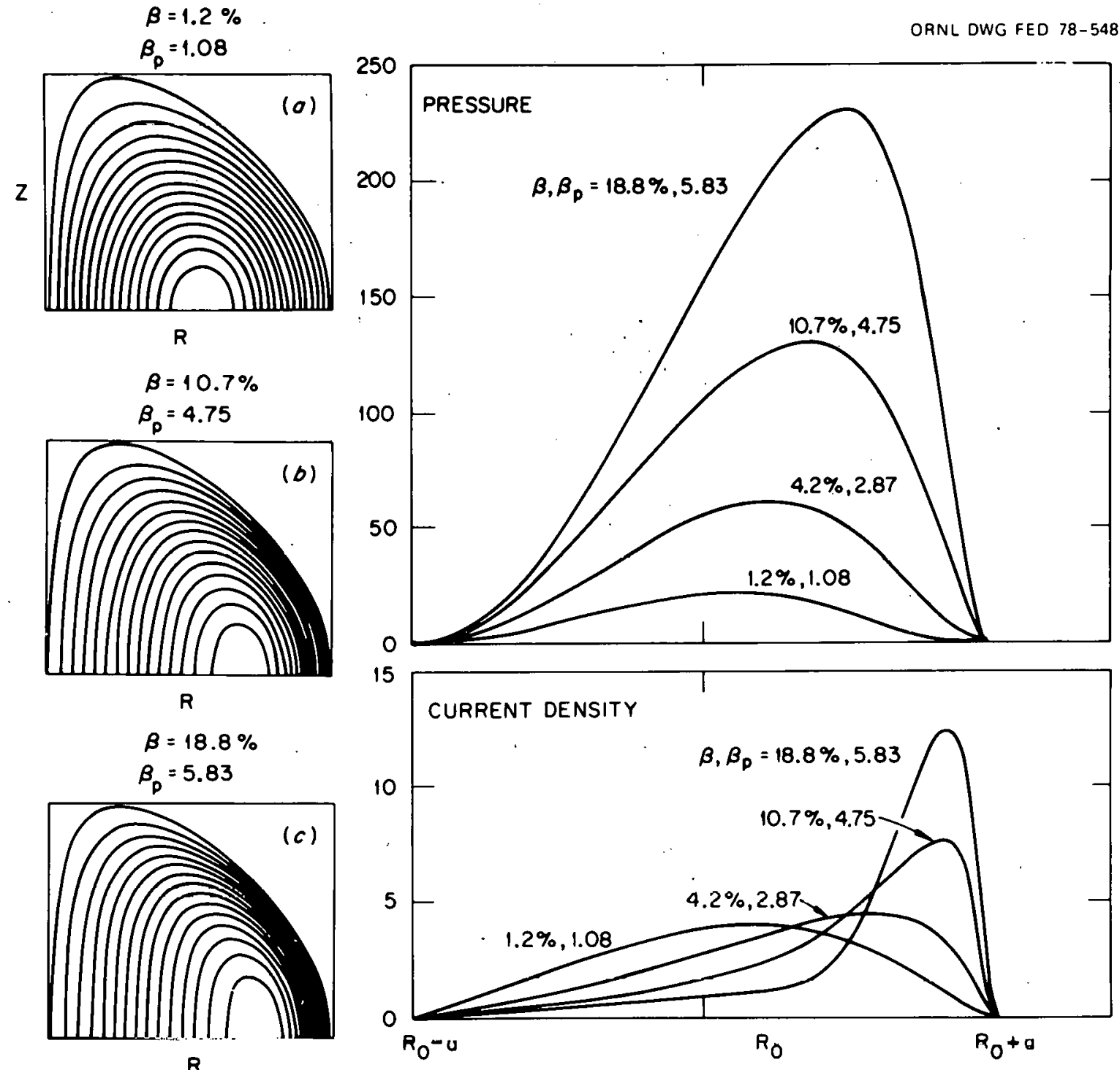

$\mathrm{R}$

Fig. 2. 
ORNL/OWG/FED $78-519$
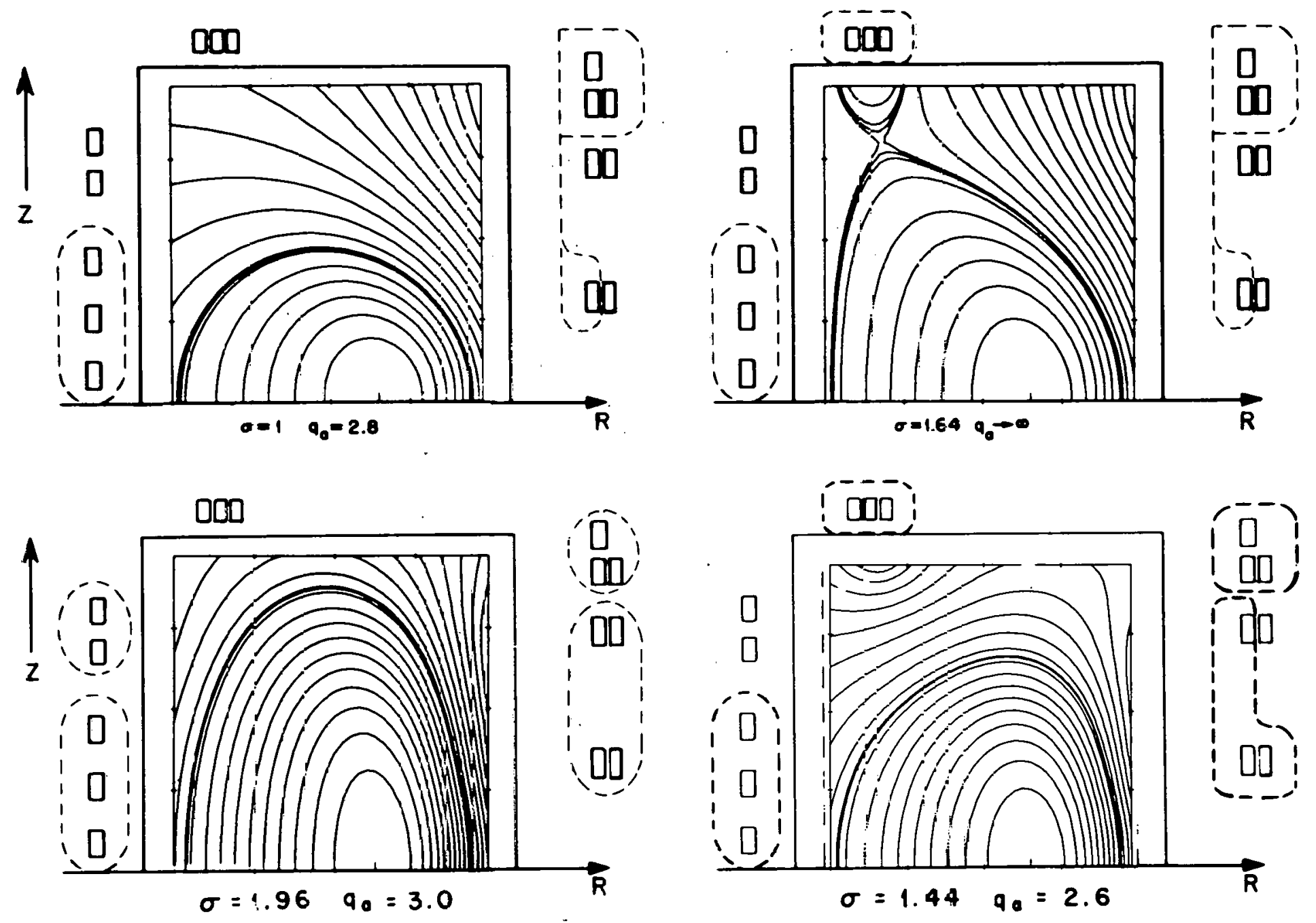

Fig. 3. 


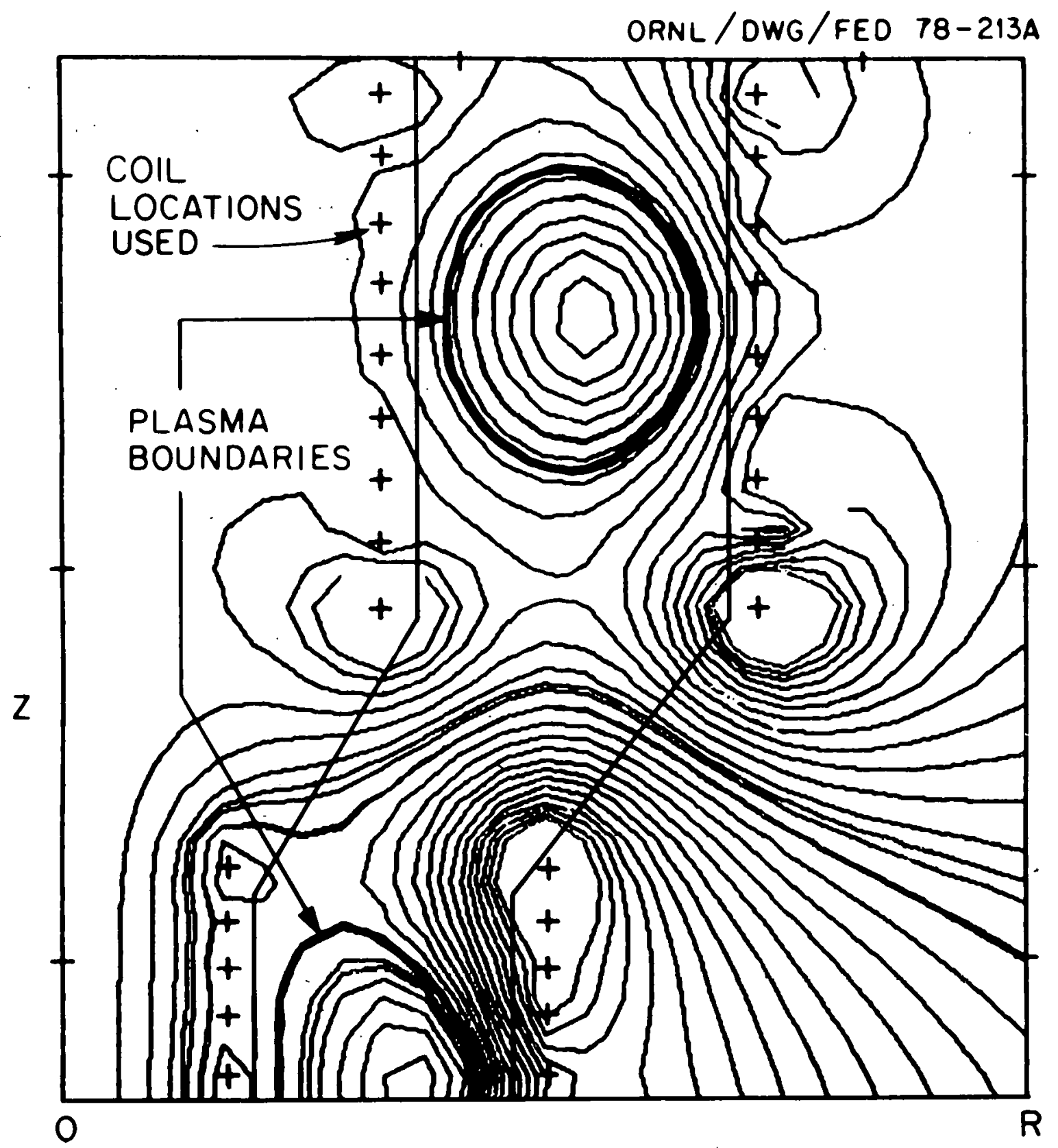

Fig. 4. 


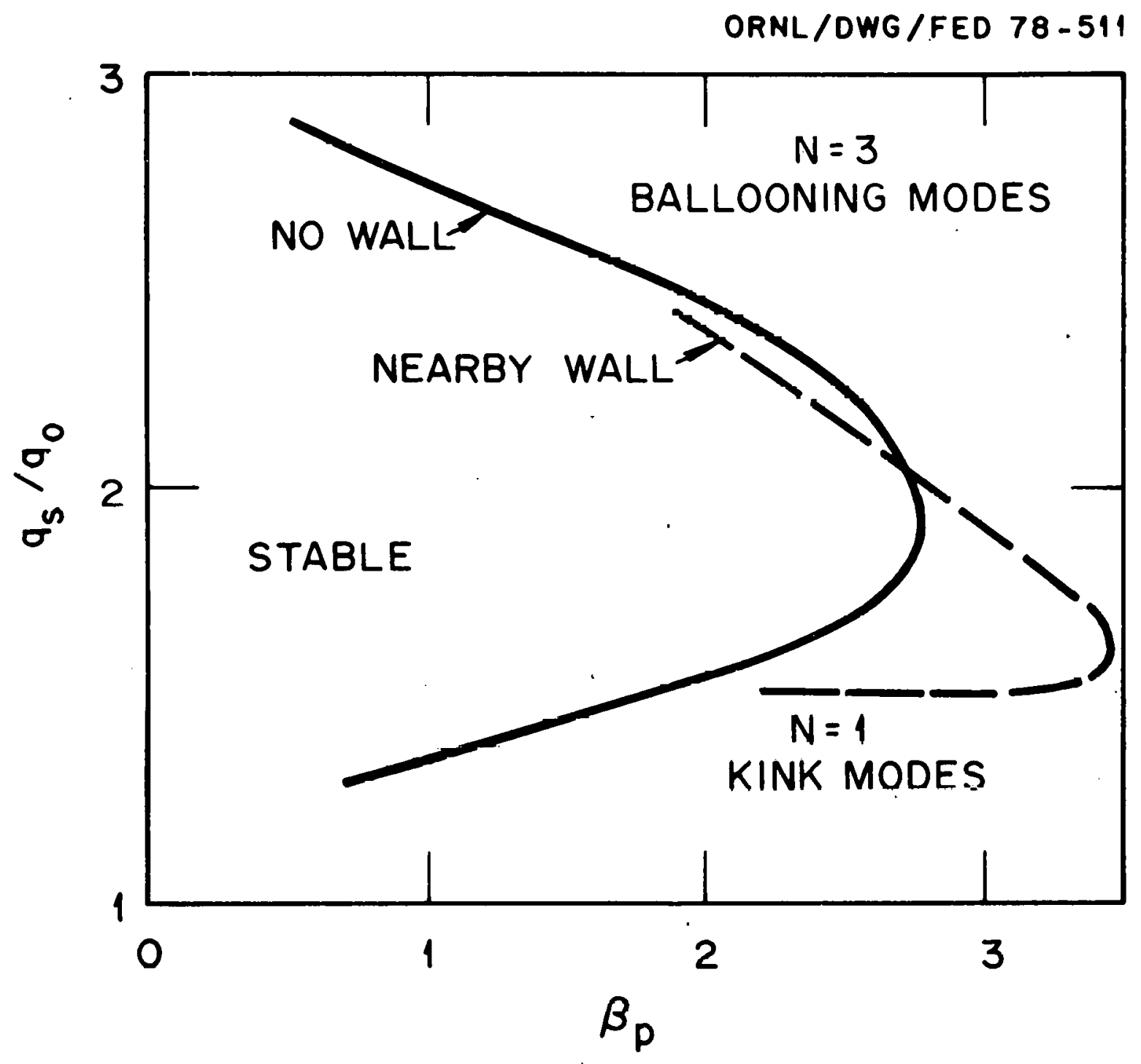

Fig. 5. 

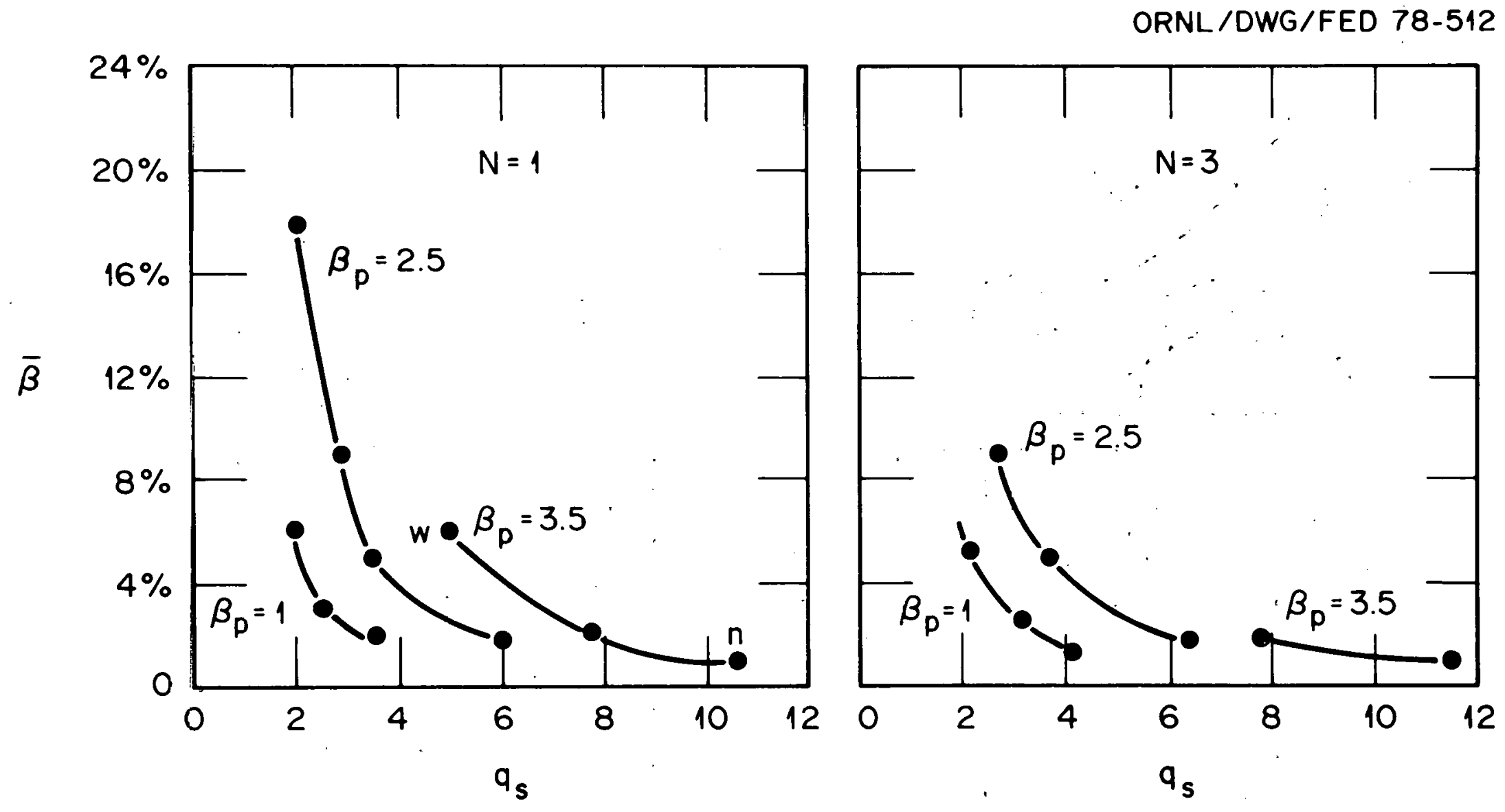

Fig. 6 . 

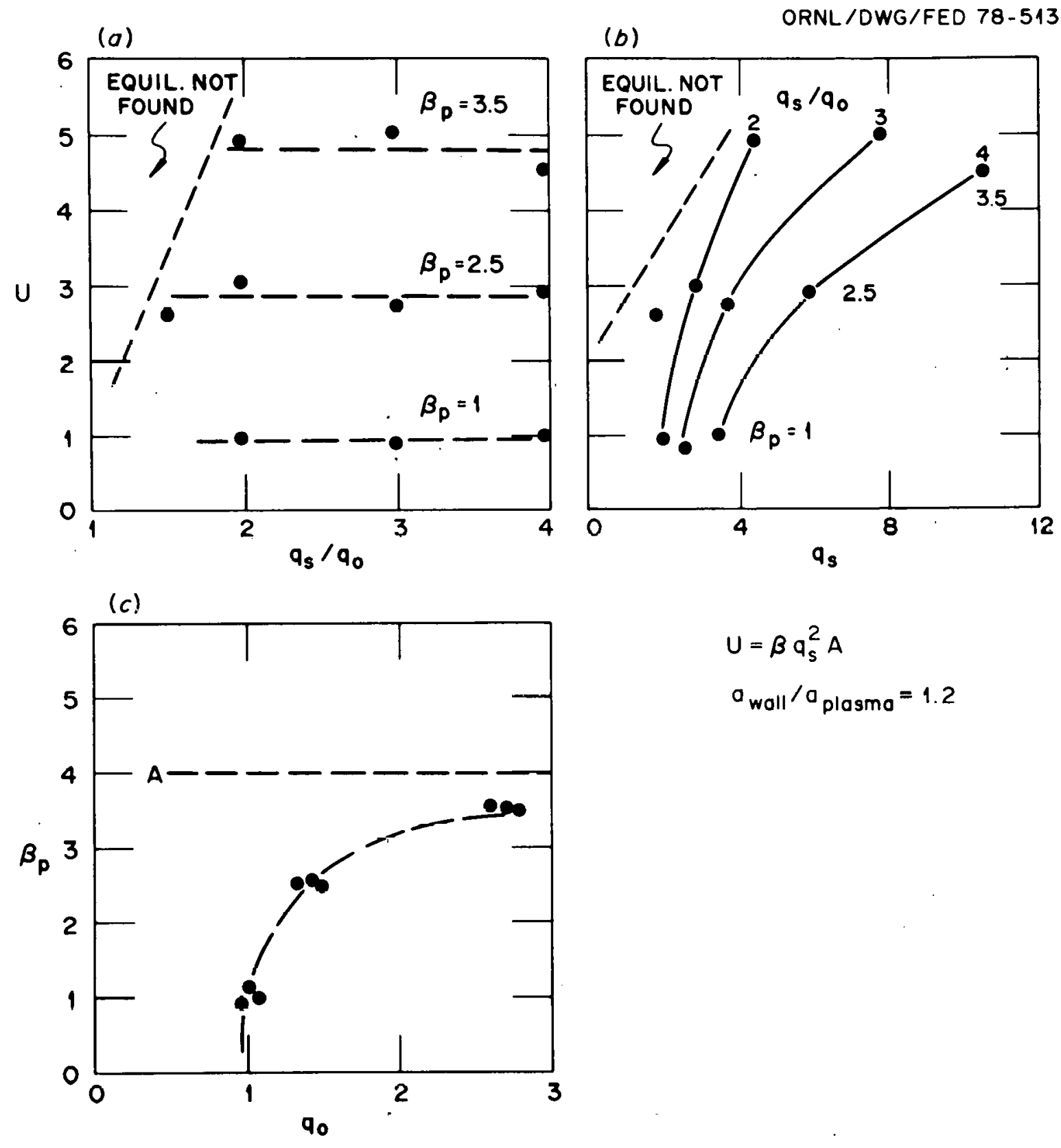

$$
\begin{aligned}
& U=\beta q_{s}^{2} A \\
& a_{\text {wall }} / a_{\text {plosmo }}=1.2
\end{aligned}
$$

Fig. 7. 


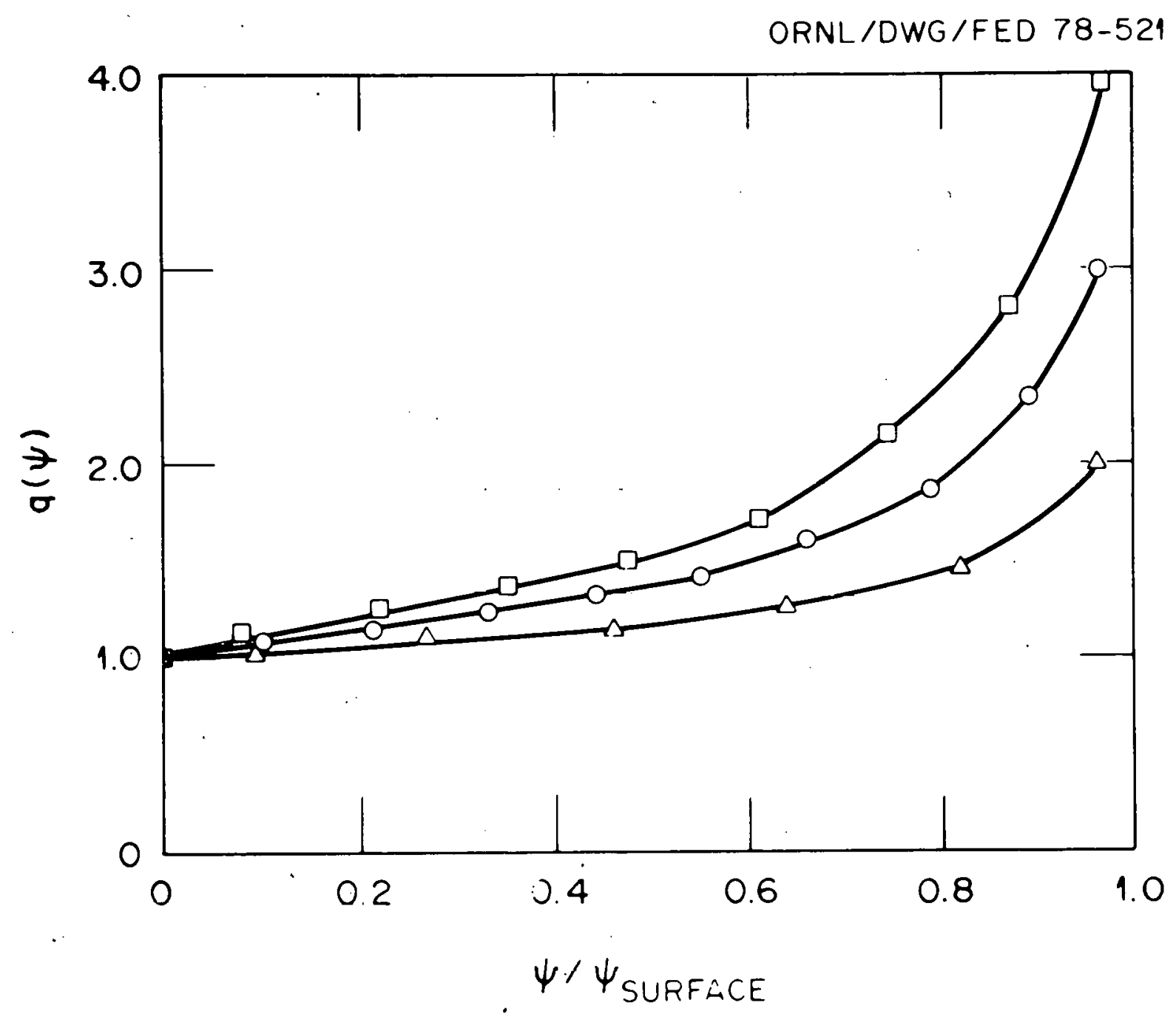

Fig. 8. 
ORNL/DWG/FED $78-514$ $U=\beta_{\text {CRIT }} q_{\text {SURF }}^{2}$ A AS FUNCTION OF PLASMA TRIANGULARITY FOR $N=\infty$ MODES

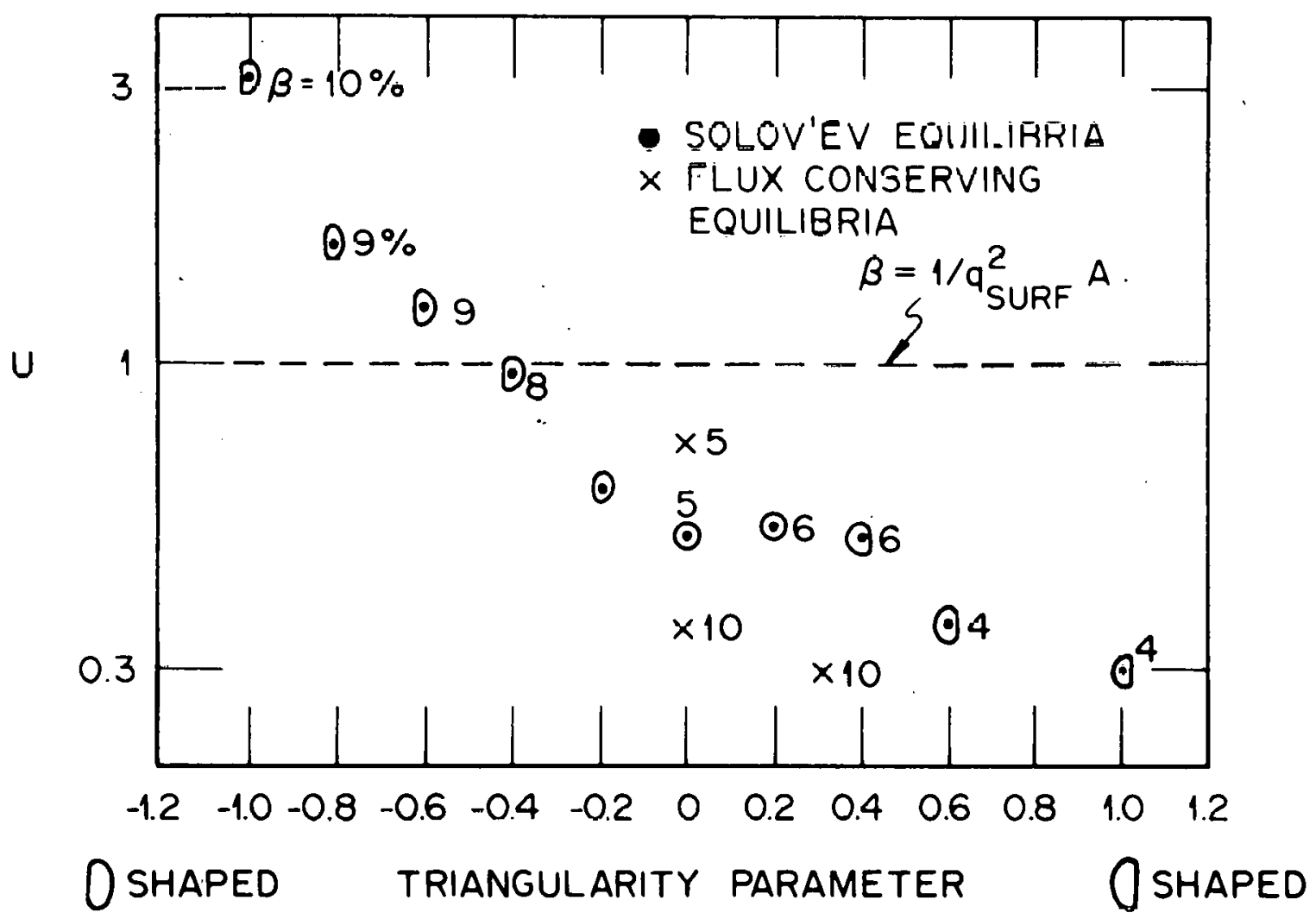

Fig. 9. . 


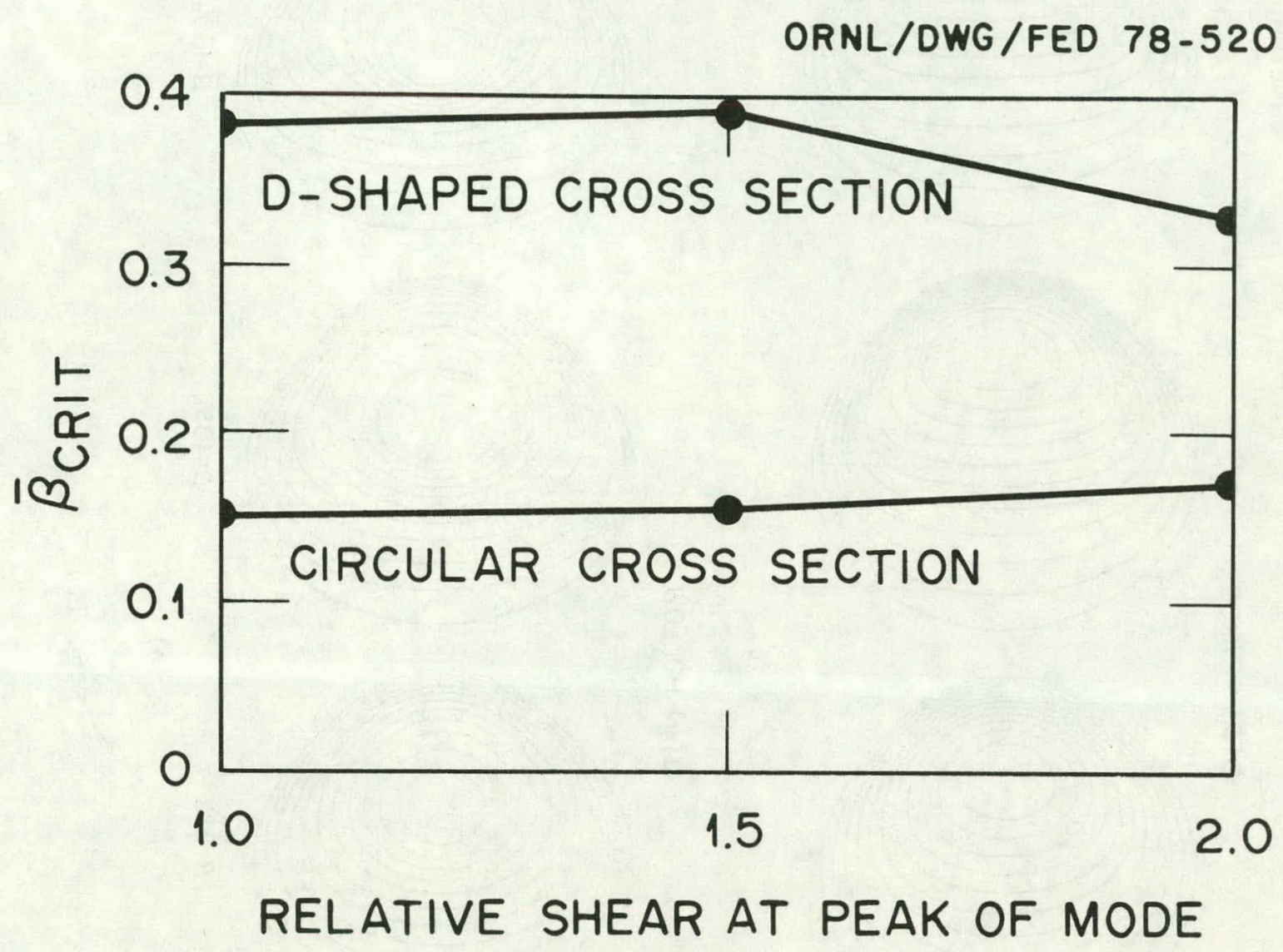

Fig. 10 . 
$Q(\psi)$ PEAKED
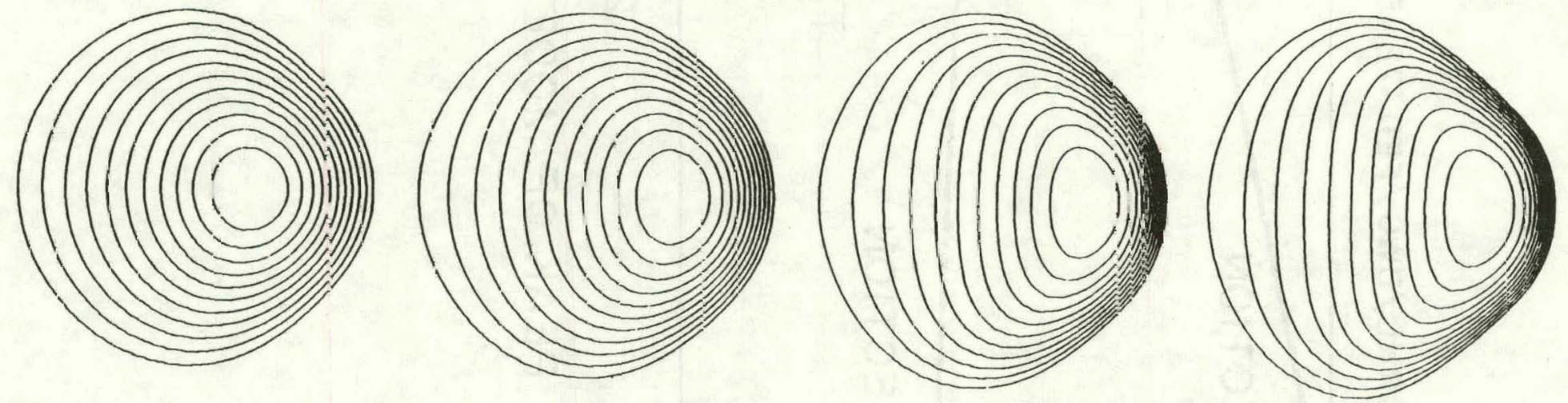

(a)

$Q(\psi)$ HOLLOW
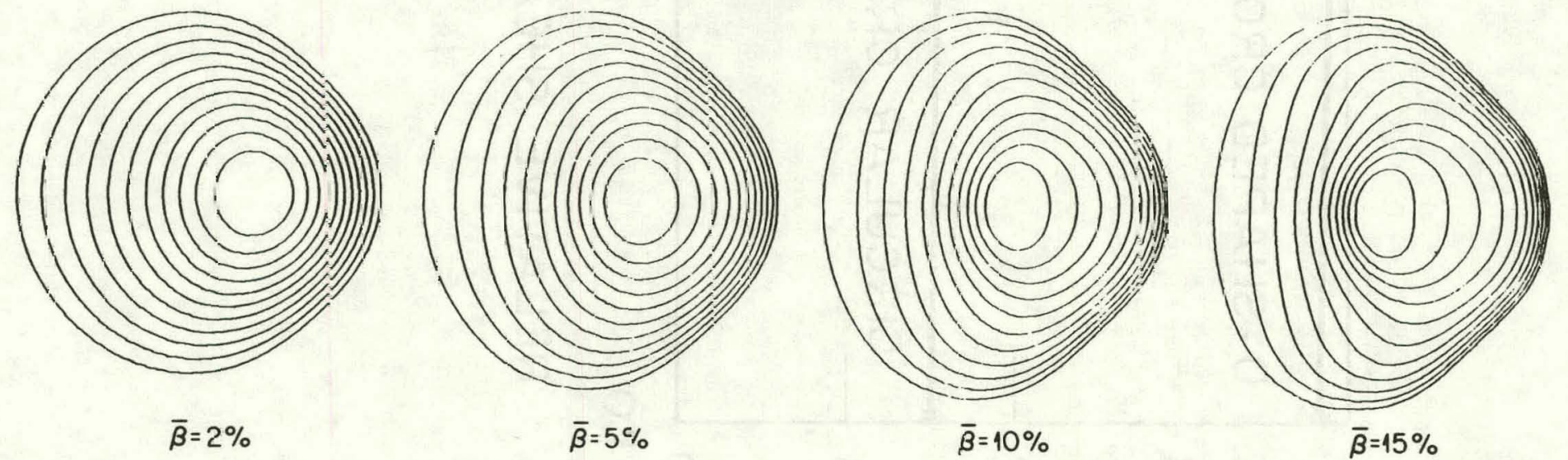

Fig. 11. 

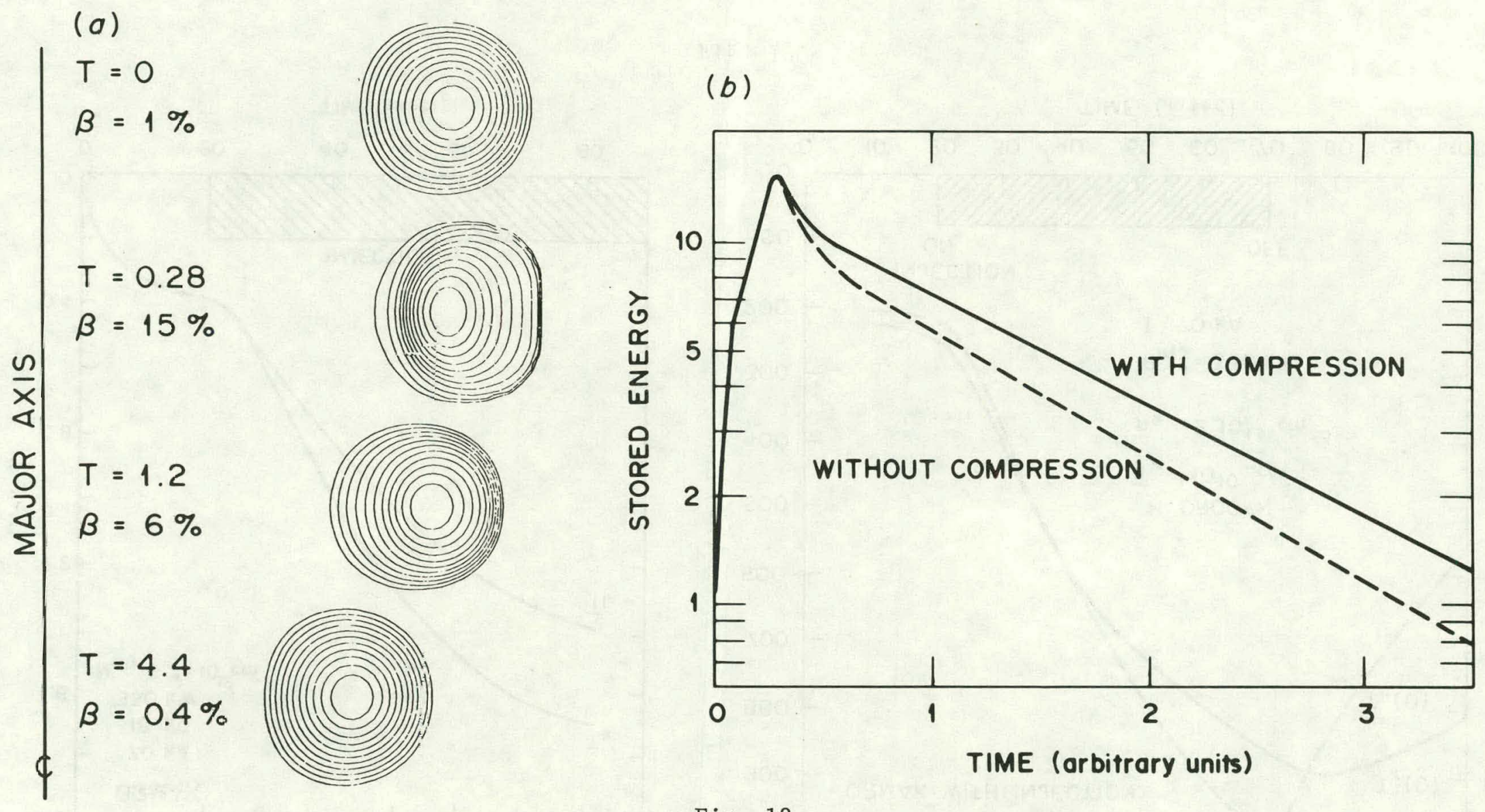

Fig. 12 . 
ORNL/DWG/FED 78-518
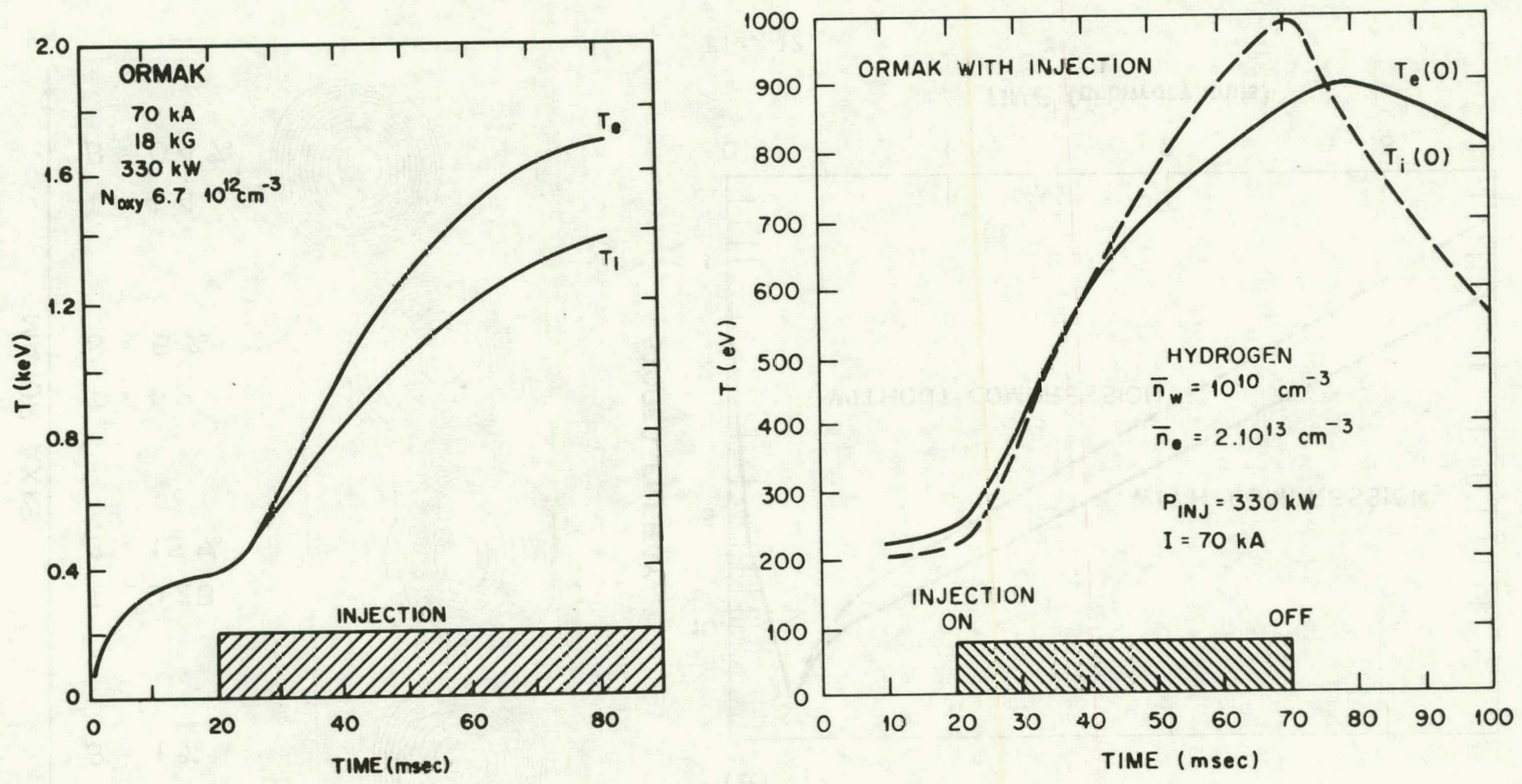

Fig. 13. 
ORNL/DWG/FED 78-517
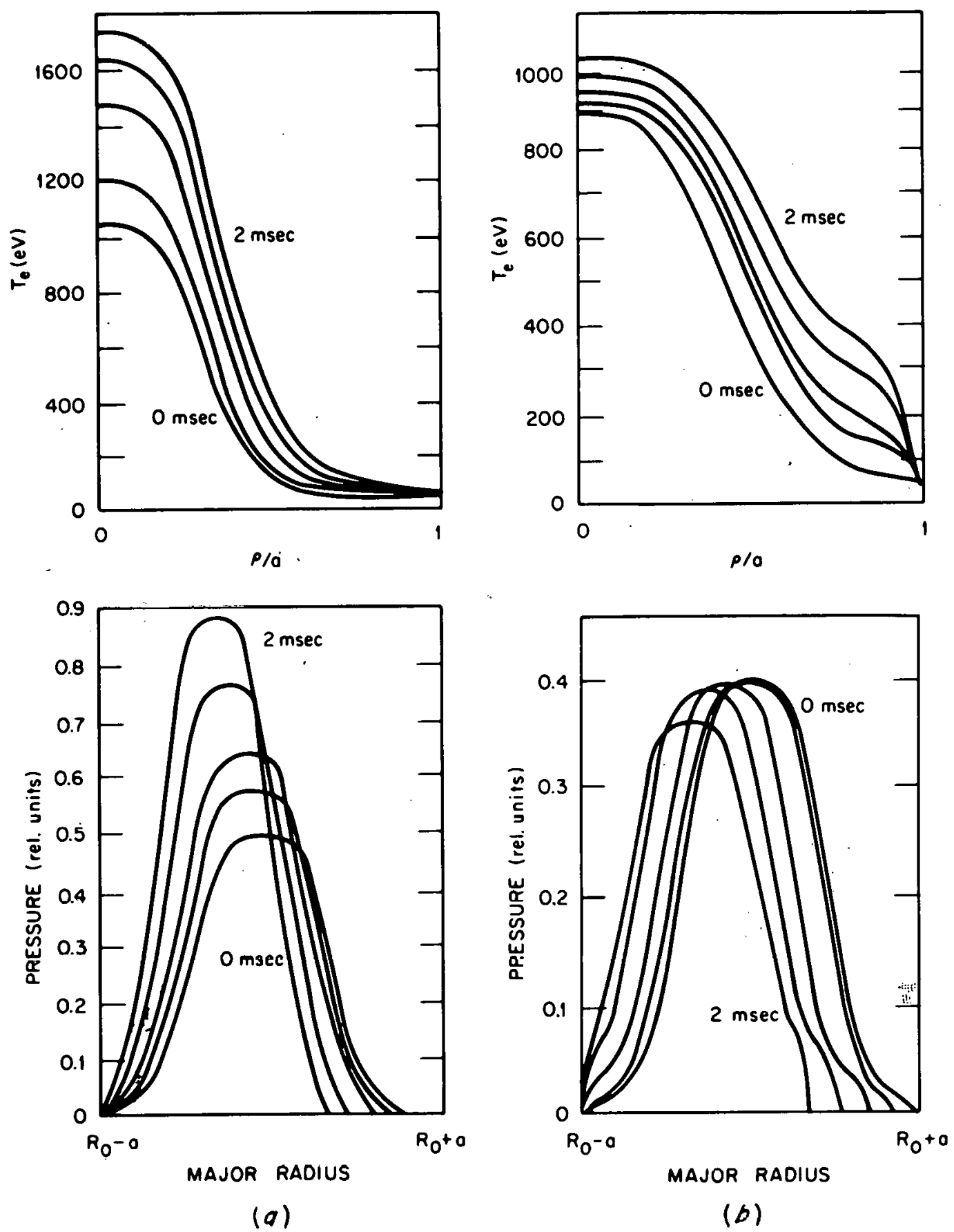

Fig. 14 . 
ORNL/DWG/FED 78-516
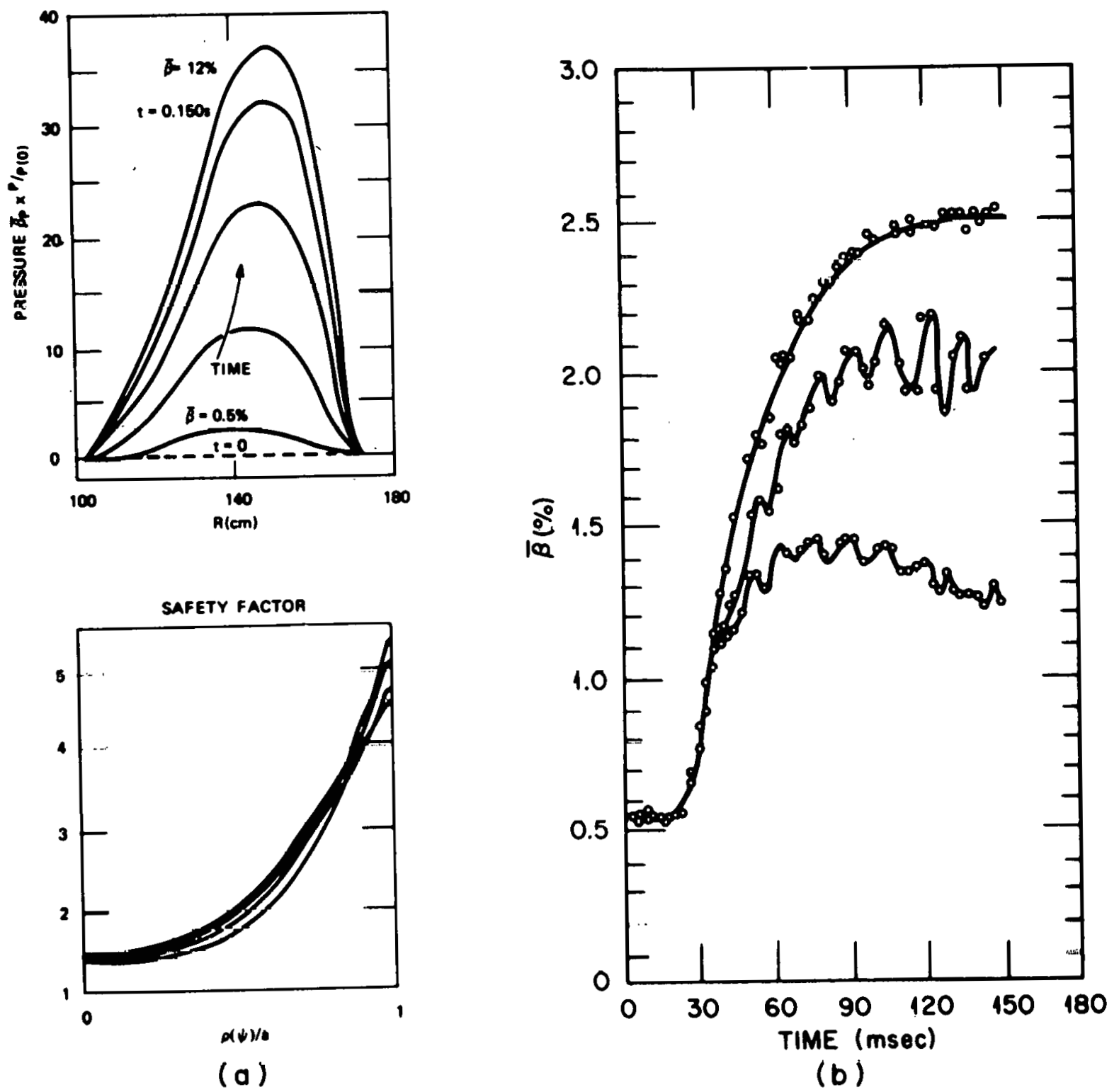

F1g. 15 . 
ORNL/TM-6434

Dist. Category UC-20 g

\section{INTERNAL DISTRIBUTION}

$\begin{aligned} \text { 1. } & \text { D. P. Berger } \\ \text { 2. } & \text { L. A. Berry } \\ \text { 3. } & \text { J. D. Callen } \\ \text { 4. } & \text { L. A. Charlton } \\ \text { 5. } & \text { R. A. Dand1 } \\ \text { 6-32. } & \text { R. A. Dory } \\ \text { 33. } & \text { H. H. Haselton } \\ \text { 34. } & \text { P. N. Haubenreich } \\ \text { 35. } & \text { J. T. Hogan } \\ \text { 36. } & \text { M. S. Lubell } \\ \text { 37. } & \text { O. B. Morgan } \\ \text { 38. } & \text { J. K. Munro } \\ \text { 39. } & \text { D. B. Nelson } \\ \text { 40. } & \text { Y-K. M. Peng }\end{aligned}$

\author{
41. H. Postma \\ 42. M. W. Rosenthal \\ 43. J. Sheffield \\ 44. D. J. Sigmar \\ 45. D. Steiner \\ 46. D. J. Strickler \\ 47-48. Laboratory Records Department \\ 49. Laboratory Records, ORNL-RC \\ 50. Document Reference Section \\ 51-52. Central Research Library \\ 53. Fusion Energy Division Library \\ 54. Fusion Energy Division \\ Communications Center \\ 55. ORNL Patent office
}

\section{EXTERNAL DISTRIBUTION}

56. D. J. Anthony, Energy Systems and Technology Division, General Electric Company, 1 River Road, B1dg. 23, Room 290, Schenectady, NY 12345

57. Bibliothek, Max-Planck Institute für Plasmaphysik, 8046 Garching bei München, Federal Republic of Germany

58. Bibliothèque, Service du Confinement des Plasmas, C.E.A., B.P. No. 6, 92, Fontenay-aux Roses (Seine), France

59. Lung Cheung; Department of Electronics, University Science Center, The Chinese Untversity of Hong Kong, Shatin, N.T., Hong Kong

60. J. F. Clarke, Office of Fusion Energy, G-234, Department. of Energy, Washington, DC 20545

61. R. W. Conn, Fusion Technology Program, Nuclear Engineering Department, University of Wisconsin, Madison, WI 53706

62. CTR Library, c/o Alan F. Haught, United Technologies Research Laboratory, East Hartford, CT 06108

63. CTR Reading Room, c/o Allan N. Kaufman, Physics Department, University of California, Berkeley, CA 94720

64. J. Narl Davidson, School of Nuclear Engineering, Georgia Institute of Technology, Atlanta, GA 30332

65. Dúcumentation S.I.G.N., Department de la Physique du Plasma et de la Fusion Controlee, Association EURATOM-CEA sur la Fusion, Centre d'Etuies Nucléaires, B.P. 85, Centre du TRI, 38041 Grenoble, Cedex, France

66. W. R. Ellis, Office of Fusion Energy, G-234, Department of Energy, Washington, DC 20545

67. Harold K. Forsen, Exxon Nuclear Co., Inc., 777 106th Avenue, N.E., C-000777, Bellevue, WA 98009

68. Harold P. Furth, Princeton Plasma Physics Laboratory, Princeton University, Forrestal. Campus, P.0. Box 451, Princeton, NJ 08540 
69. Roy W. Gould, California Institute of Technology, Mail Stop 116-81, Pasadena, CA 91125

70. Robert L. Hirsch, Exxon Research and Engineering, P.0. Box 101, Florham Park, NJ 07932

71. Raymond A. Huse, Manager, Research and Development, Public Service Gas and Electric Company, 80 Park Place, Newark, NJ 07101

72. T. Hsu, Office of Fusion Energy, G-234, Department of Energy, Washington, DC 20545

73. V. E. Ivanov, Physical-Technical. Institute of the Ukranian Academy of Sclences, Sukhumi, U.S.S.R.

74. A. Kadish, Off1ce of Fusion Energy, G-234, Department of Energy, Washington, DC 20545

75. L. M. Kovrizhnikh, Tebedev Institutc of Physics, Academy of Sciences of the U.S.S.R., Teninsky Prospert 53, Moscow, U.S.S.S.R.

76. Guy Laval; Groupe de Physlque Thëorique, Ecole Polytechnique, 91 Palaiseau, Paris, France

77. Library, Centre de Recherches en Physique des Plasma, 21 Avenue des Bains, 1007, Lausanne, Switzerland

78. Library, Culham Laboratory, United Kingdom Atomic Energy Authority, Abingdon, Oxon, OX14 3DB, United Kingdom

79. Library, FOM-Institut voor Plasma - Fysica, Rijnhuizen, Jutphaas, Netherlands

80. Library, Institute for Plasma Physics, Nagoya University, Nagoya, Japan 464

81. Library, International Centre for Theoretical Physics, Trieste, Italy

82. Library, Laboratorio Gas Ionizzati, Fraccati, Italy

83. Dsumber G. Lominadze, Academy of Sciences of the Georgian S.S.R., 8 Dzerzhinski St., 38004, Tbilisi, U.S.S.R.

84. Oscar P. Manley, Office of Fusion Energy, G-234, Department of Energy, Washington, DC 20545

85. D. G. McAlees, Exxon Nuclear Co., Inc., Research and Technology Laser Enrichment Department, 2955 George Washington Way, Richland, WA 99352

86. J. E. McCune, School of Engineering, Department of Aeronautics and Astronautics, B1dg. 37-391, Massachusetts Institute of Technology, Cambridge, MA 02139

87. Claude Mercier, Service du Theorie des Plasmas, Contre d'Études Nucléaires, Fontenay-aux-Roses (Seine), France

88. K. G. Moses, Office of Fusion Energy, G-2.34, Mepartment of Energy, Washington, DC 20545

89. D. Pfirsch, Institule for Plasma Physics, 8046 Garching bei München, Federal Republic of Germany

90. Plasma Physics Group, Department of Engineering Physics, Australian National University, P.0. Box 4, Canberra A.C.T. 2600, Australia

91. A. Kogister, Institute for Plasma Physics, KFA, Postfach 1913, D-5170, Jülich 1, Federal Republic of Germany

92. W. Sadowski, Office of Fusion Energy, G-234, Department of Energy, Washington, DC 20545 
93. V. D. Shafranov, I. V. Kurchatov Institute of Atomic Energy, 46 Ulitsa Kurchatova, P.O. Box 3402, Moscow, U.S.S.R.

94. Yu. S. Sigov, Institute of Applied Mathematics of the U.S.S.R. Academy of Sciences, Miuskaya, Sq. 4, Moscow A-47, U.S.S.R.

95. W. M. Stacey, Jr., School of Nuclear Engineering, Georgia Institute of Technology, Atlanta, GA 30332

96. J. B. Taylor, Culham Laboratory, United Kingdom Atomic Energy Authority, Abingdon, Oxon, 0X14 3DB, United Kingdom

97. Thermonuclear Library, Japan Atomic Energy Research Institute, Tokai, Naka, Ibaraki, Japan

98. Francisco Verdaguer, Director, Division of Fusion, Junta de Energia Nuclear, Madrid 3, Spain

99. Director, Research and Technical Support Division, Department of Energy, Oak Ridge Operations, P.O. Box E, Oak Ridge, TN 37830

101-276. Given distribution as shown in TID-4500, Magnetic Fusion Energy (Distribution Category UC-20g, Theoretical Plasma Physics) 